
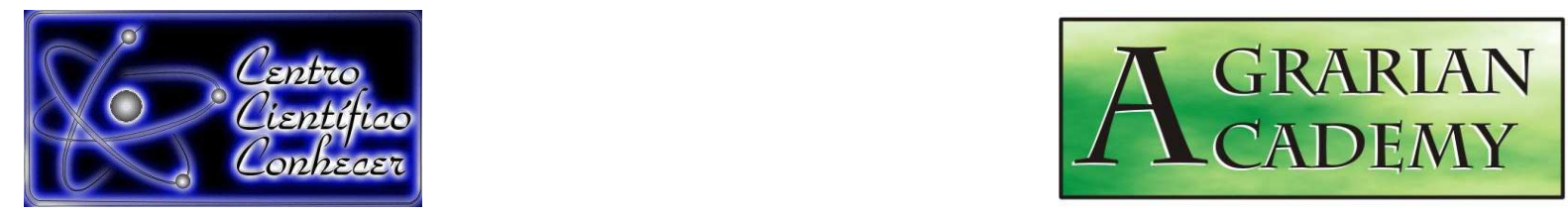

\title{
ALTERAÇÕES FLORÍSTICAS E ESTRUTURAIS EM FLORESTA COM ARAUÇÁRIA NO ESTADO DO RIO GRANDE DO SUL, BRASIL
}

Ângelo Augusto Ebling ${ }^{1}$, Pompeu Paes Guimarães ${ }^{2}$, Allan Libanio Pelissari ${ }^{3}$, Simone Filipini Abrão ${ }^{3}$, Rodrigo Otávio Veiga de Miranda ${ }^{3}$

${ }^{1}$ Doutorando, Programa de Pós-graduação em Engenharia Florestal da Universidade Federal do Paraná, Curitiba, Paraná, Brasil

e-mail: aebling@hotmail.com

${ }^{2}$ Professor da Universidade Federal Rural do Semi-Árido, Mossoró, Rio Grande do

Norte, Brasil

${ }^{3}$ Doutorandos, Programa de Pós-graduação em Engenharia Florestal da

Universidade Federal do Paraná, Curitiba, Paraná, Brasil

Recebido em: 03/01/2014 - Aprovado em: 04/04/2014 - Publicado em: 12/04/2014

\section{RESUMO}

O conhecimento dos processos dinâmicos que envolvem as florestas é essencial para a compreensão do funcionamento, direcionamento do manejo e subsídio de informações para a recuperação e restauração florestal. Diante do exposto, o estudo tem como objetivo analisar as alterações florísticas e estruturais de uma Floresta com Araucária, localizada no município de São Francisco de Paula, RS. Para isso, utilizaram-se informações de dez conglomerados permanentes de 100x100m, remedidos anualmente por processo de inventário florestal contínuo. Todos os indivíduos com diâmetro a altura do peito (DAP) maior ou igual a 9,5 cm foram mensurados, identificados e classificados de acordo com seus respectivos grupos ecológicos. As avaliações da dinâmica da floresta foram confrontadas com dados meteorológicos locais. A análise da estrutura horizontal mostrou elevada densidade e dominância. Araucaria angustifolia e Myrtaceae foram respectivamente a espécie e família de maior importância na floresta. O grupo ecológico com maior representatividade foi o secundário tardio. As taxas referentes a mortalidade superaram as de recrutamento, sugerindo uma gradual redução da densidade, embora tenha ocorrido aumento de área transversal, justificando o avanço sucessional da floresta. Os recrutamentos e mortalidade apresentaram relação com dados de precipitação, ocorrendo as maiores taxas de mortalidade no período de estiagem. De modo geral, a floresta não sofreu alterações profundas no período de dez anos, embora tenham sido observados períodos com baixa precipitação, que influenciaram a estrutura e florística, evidenciando a capacidade de resiliência florestal.

PALAVRAS-CHAVE: Estrutura Florestal, Fitossociologia, Floresta ombrófila mista

\section{FLORISTIC AND STRUCTURAL CHANGES IN ARAUCARIA FOREST IN RIO GRANDE DO SUL STATE, BRAZIL}




\begin{abstract}
The knowledge of the dynamic processes that involve forests is essential for understanding the operation, management, restoration and recuperation forest. Given the above, the study aims to analyze the floristic and structural changes of an Araucaria Forest, located in the municipality of São Francisco de Paula, RS, Brazil. For this, we used information from ten permanent conglomerates $100 \times 100 \mathrm{~m}$, remeasured annually by continuous forest inventory process. All individuals with diameter as height breast greater than or equal to $9.5 \mathrm{~cm}$ were measured, identified and classified according to their ecological groups. The evaluation of dynamics forest was confronted with local meteorological data. The horizontal structure analysis, indicate a high density and dominance. Araucaria angustifolia and Myrtaceae were respectively the species and family with major importance in the forest. The ecological group with largest representation was secondary late. The rates for mortality exceeded the recruitment, suggesting a gradual reduction in density, although there was increased of basal area, justifying the forest successional advancement. Recruitment and mortality, were associated with rainfall data, the highest mortality rates were in the dry season. In general, the forest not indicated profound changes in the ten-year period, although periods with low rainfall, which influence the structure and floristic, demonstrating the ability of forest resilience have been observed.
\end{abstract}

KEYWORDS: Forest Structure, Mixed Ombrophylous Forest, Phytosociology

\title{
INTRODUÇÃO
}

O Brasil concentra uma ampla cobertura florestal, abrangendo 516 milhões de hectares, sendo que deste total 98,7\%, correspondem à cobertura de florestas naturais (SFB, 2010). As modificações impostas pela atividade antrópica foram igualmente amplas nestas áreas, e como resultado, hoje tem-se uma estrutura e composição de florestas bastante alteradas quando comparadas a original (GALVÃO \& AUGUSTIN, 2011). Considerando os benefícios sociais e culturais que as florestas naturais propiciam, como por exemplo, a conservação e estabilidade do meio ambiente, fonte energética e de matéria-prima, são necessários estudos que possibilitem o maior entendimento dos processos dinâmicos florestais, subsidiando ações legais e o aproveitamento racional deste recurso (WATZLAWICK et al., 2011; LIMA et al., 2012; EBLING et al., 2012).

Nesse sentido, o manejo florestal vem ao encontro das necessidades conservacionistas e do suprimento por matéria prima, mantendo o equilíbrio do ecossistema e disponibilidade futura de recursos. Entretanto, a efetivação do manejo é dependente do entedimento de uma gama de processos envolvendo a autoecologia e sinecologia de uma comunidade vegetal, que por sua vez, constitui em um dos grandes problemas das ciências florestais, devido sua complexidade e dificuldade de interpretação quanto às múltiplas implicações do ecossistema (SCHNEIDER \& FINGER, 2000).

Considerando a riqueza florística das florestas brasileiras, o bioma Mata Atlântica destaca-se com grande número de endemismos e complexas fitofisionomias, entre estas, destaca-se no Planalto Meridional brasileiro a Floresta Ombrófila Mista, que conta com gêneros primitivos afro-asiáticos como Podocarpus e australásios como Drymis e Araucaria. Logo, justifica-se a denominação da formação fitogeográfica como Floresta com Araucária.

AGRARIAN ACADEMY, Centro Científico Conhecer - Goiânia, v.1, n.01; p. 2 
Estima-se que a área originalmente ocupada pela Floresta com Araucária era de aproximadamente $200.000 \mathrm{~km}^{2}$ (KANIESKI et al., 2010), sendo esta distribuída: $40 \%$ sobre o estado do Paraná, 31\% em Santa Catarina, 25\% no estado do Rio Grande do Sul e 4\% em manchas esparsas nos estados de São Paulo, Rio de Janeiro e Minas Gerais (CARVALHO, 1994). Seguindo o modelo da Mata Atlântica, que teve sua abrangência natural reduzida em 92\%, a Floresta com Araucária sofreu um profundo processo de degradação, essencialmente na segunda metade do século passado, cedendo espaço para novas fronteiras agrícolas (PIRES et al., 2012).

Diante do exposto o presente estudo tem como objetivos contribuir e alicerçar a literatura existente, por meio da análise das alterações florísticas e estruturais de um remanescente de Floresta com Araucária, disponibilizando informações que possam ser úteis quanto ao direcionamento de projetos relacionados a recuperação, restauração, manejo sustentado e compreensão dos processos dinâmicos das florestas naturais.

\section{MATERIAL E MÉTODOS}

O estudo foi realizado na Floresta Nacional de São Francisco de Paula, RS, localizada entre as coordenadas 2924 e 2927' de I atitude Sul e 5022' e 50'25' de longitude Oeste, na mesorregião nordeste do estado do Rio Grande do Sul, Microrregião de Vacaria. A área da Flona abrange 1.606 ha, sendo que desse total, 900 ha são ocupados por vegetação natural, com trechos de campo nativo (estepe), banhados, sendo a Floresta com Araucária a vegetação predominante.

A altitude média do local é de 900 metros, variando esse valor para mais ou menos 300 metros, considerando que o relevo no local é ondulado a fortemente ondulado, com cânions de até 100 metros de profundidade. Os solos predominantes na região são classificados como Cambissolo Húmico Alumínico, Chernossolo Argilúvico Férrico e Neossolo Litólico Eutrófico, derivados de rochas efusivas básicas e ácidas da Formação Serra Geral.

De acordo com a classificação global dos tipos climáticos desenvolvidos por Köppen, o clima da região é do tipo "Cfb", mesotérmico e superúmido, com verão brando e inverno frio. A formação de geadas é frequente, com queda de neve nos meses mais frios. A proximidade do oceano Atlântico associada à grande altitude propiciam valores de precipitação bastante elevados $(2.252 \mathrm{~mm} / \mathrm{ano})$, distribuídos de forma regular por todo o ano (NIMER, 1990). MALUF (1999) descreve uma precipitação local pouco inferior, igual a $2.162 \mathrm{~mm} / \mathrm{ano}$, igualmente com chuvas bem distribuídas por todo ano, sem ocorrência de déficit hídrico.

O banco de dados empregados nesse estudo é proveniente de 10 conglomerados com área de um ha $(100 \times 100 \mathrm{~m})$ cada, distribuídos em locais heterogêneos dentro da vegetação natural da área. Instalados em 1999, os conglomerados foram remedidos anualmente entre os anos de 2000 a 2009, empregando um sistema de amostragem com repetição total.

Dessa forma, todos os indivíduos arbóreos inseridos na área amostral, cujo diâmetro a altura do peito fosse igual ou superior a $9,5 \mathrm{~cm}$ (DAP $\geq 9,5)$ foram avaliados. A identificação botânica foi realizada em nível de espécie, e cada indivíduo teve suas características dendrométricas mensuradas, além de receber identificação permanente e marcação da altura de coleta dos diâmetros. As nomenclaturas adotadas seguem o padrão sugerido pelo Angiosperm Philogeneny Group III (APG III, 2009). 
A análise da alteração na composição florística foi realizada por meio da ocorrência ou ausência de cada indivíduo no momento das remedições. Foram avaliados e quantificados todos os indivíduos, suas respectivas espécies, gêneros e famílias inseridas nos conglomerados.

A estrutura horizontal foi descrita pelos parâmetros quantitativos usualmente empregados na fitossociologia: densidade, dominância, frequência e seus respectivos valores relativos além dos valores de cobertura e importância. Os parâmetros foram analisados nas ocasiões do primeiro e último inventário.

Com o objetivo de complementar as análises, cada espécie teve um grupo ecológico associado, possibilitando relacionar o predomínio de cada grupo, da mesma forma que a similaridade das espécies em função de seus grupos correspondentes. BUDOWSKI (1965) cita características diversas que permitem agrupar diferentes espécies em grupos ecológicos iguais. Porém, o mesmo autor descreve a tolerância ou não ao sombreamento como principal critério de formação dos grupos. Com o objetivo de identificar os grupos ecológicos de cada espécie, foram identificadas na literatura a classificação de grupo correspondente, e caso verificada a ausência de dados bibliográficos, a classificação dos grupos ocorria "in loco", de acordo com características relacionadas à tolerância ao sombreamento, crescimento e regeneração do sub-bosque, descritas por BUDOWSKI (1965) no quadro 1.

QUADRO 1 - Características avaliadas para a classificação dos grupos ecológicos empregada nas espécies arbóreas. Adaptado de BUDOWSKI, 1965

\begin{tabular}{cccc}
\hline $\begin{array}{c}\text { Grupo } \\
\text { Ecológico }\end{array}$ & Regeneração & Crescimento & $\begin{array}{c}\text { Tolerância ao } \\
\text { sombreamento }\end{array}$ \\
\hline Pioneira & Muito Baixa & Muito rápido & Muito intolerante \\
\hline $\begin{array}{c}\text { Secundária } \\
\text { Inicial }\end{array}$ & Baixa & Muito rápido & Muito intolerante \\
\hline $\begin{array}{c}\text { Secundária } \\
\text { Tardia }\end{array}$ & $\begin{array}{c}\text { Baixa ou alta, com } \\
\text { elevada mortalidade } \\
\text { na fase inicial }\end{array}$ & Lento a rápido & $\begin{array}{c}\text { Tolerante no estágio inicial, } \\
\text { após intolerante }\end{array}$ \\
\hline Clímax & Alta & Muito lento & $\begin{array}{c}\text { Tolerante no estágio inicial, } \\
\text { após intolerante }\end{array}$ \\
\hline
\end{tabular}

Como a espécie Araucaria angustifolia apresenta peculiaridades quanto a sua classificação em um grupo ecológico preferencial, optou-se por desconsiderar sua classificação, uma vez que esta espécie mantém características tanto pioneiras como climáxicas (SOARES, 1979).

A ocorrência do recrutamento foi verificada no momento em que novos indivíduos atingissem o diâmetro mínimo limite para a inclusão (DAP $\geq 9,5)$ na ocasião das remedições anuais do inventário contínuo. A taxa de recrutamento foi calculada pela expressão:

$$
R \%=\frac{N}{N s \cdot n} \cdot 100
$$

Em que:

$R \%=$ taxa anual de recrutamento;

$N$ = número de árvores recrutadas no período;

AGRARIAN ACADEMY, Centro Científico Conhecer - Goiânia, v.1, n.01; p. 4 
Ns = número de árvores vivas no período;

$n=$ intervalo entre as medições.

A mortalidade foi verificada na ocasião em que um indivíduo vivo mensurado na ocasião de um primeiro inventário, e que teve sua morte verificada em um segundo momento. A taxa de mortalidade foi calculada pela expressão:

$$
M \%=\frac{M}{N s \cdot n} \cdot 100
$$

Em que:

$M \%$ = taxa anual de recrutamento;

$M=$ número de árvores que morreram no período;

$N s$ = número de árvores vivas no período;

$n=$ intervalo entre as medições.

Foram realizadas análises quantitativas e gráficas entre espécies, famílias e grupos ecológicos, tanto para mortalidade quanto para o recrutamento. Buscando complementar a análise dinâmica da floresta, foram avaliadas suas relações com as variações meteorológicas, com dados procedentes de uma estação meteorológica do Instituto Nacional de Meteorologia (INMET), instalada no município de Cambará do Sul, RS (Estação № 83946). A estação se localiza na latitude 2905' Sul e 50`3' de longitude Oeste, a uma altitude de 905 metros acima do nível do mar, a uma distância de aproximadamente $40 \mathrm{~km}$ da área de estudo.

Empregando análise de correlação entre os dados foram testadas a interação entre recrutamento, mortalidade e crescimento diamétrico com as variáveis: precipitação, insolação, umidade relativa, temperatura média, temperatura máxima e temperatura mínima. Os valores relativos aos dados meteorológicos utilizados na matriz de correlação foram agrupados mensalmente, para os 10 anos amostrados.

\section{RESULTADOS E DISCUSSÃO}

As espécies arbóreas encontradas no local de estudo estão relacionadas no quadro 2, no qual constam respectivamente, nomes científicos, nomes populares, famílias botânicas e classificação pelo grupo ecológico preferencial. Ressalta-se a presença de 16 indivíduos que foram mensurados, porém não puderam ser identificados por apresentarem material botânico insuficiente, sendo estes agrupados como uma única espécie, denominada "Não Identificada" (NI).

QUADRO 2 - Análise da composição florística e grupos ecológicos encontrados no estrato

\begin{tabular}{lllc}
\hline \multicolumn{1}{c}{ Nome Científico } & Nome Popular & $\begin{array}{c}\text { Família } \\
\text { Botânica }\end{array}$ & $\begin{array}{c}\text { Grupo } \\
\text { Ecológico }\end{array}$ \\
\hline $\begin{array}{l}\text { Acacia bonariensis Gillies ex } \\
\text { Hook. \& Arn. }\end{array}$ & Unha-de-gato & Fabaceae & $\mathrm{Pi}^{5}$ \\
\hline $\begin{array}{l}\text { Acca sellowiana (O. Berg) } \\
\text { Burret }\end{array}$ & $\begin{array}{l}\text { Goiaba-da- } \\
\text { serra }\end{array}$ & Myrtaceae & $\mathrm{Si}^{5}$ \\
\hline $\begin{array}{l}\text { Allophylus edulis (A. St.-Hil., } \\
\text { Cambess. \& A. Juss.) Radlk. }\end{array}$ & Chal-chal & Sapindaceae & $\mathrm{Si}^{1}$ \\
\hline
\end{tabular}




\begin{tabular}{|c|c|c|c|}
\hline Nome Científico & Nome Popular & $\begin{array}{l}\text { Família } \\
\text { Botânica }\end{array}$ & $\begin{array}{c}\text { Grupo } \\
\text { Ecológico }\end{array}$ \\
\hline Alsophila sp. & $\begin{array}{l}\text { Xaxim-de- } \\
\text { espinho }\end{array}$ & Cyatheaceae & $\mathrm{Cl}^{10}$ \\
\hline $\begin{array}{l}\text { Annona rugulosa (Schltdl.) H. } \\
\text { Rainer }\end{array}$ & Ariticum & Annonaceae & $\mathrm{Si}^{10}$ \\
\hline $\begin{array}{l}\text { Annona salicifolia Ekman \& } \\
\text { R.E. Fr. }\end{array}$ & Ariticum & Annonaceae & $\mathrm{St}^{1}$ \\
\hline $\begin{array}{l}\text { Araucaria angustifolia (Bertol.) } \\
\text { Kuntze }\end{array}$ & Araucária & $\begin{array}{l}\text { Araucariacea } \\
\mathrm{e}\end{array}$ & \\
\hline $\begin{array}{l}\text { Banara parviflora (A. Gray) } \\
\text { Benth. }\end{array}$ & $\begin{array}{l}\text { Guaçatunga- } \\
\text { preta }\end{array}$ & Salicaceae & $\mathrm{St}^{4}$ \\
\hline Banara tomentosa Clos & $\begin{array}{l}\text { Guacatunga- } \\
\text { branca }\end{array}$ & Salicaceae & $\mathrm{St}^{4}$ \\
\hline $\begin{array}{l}\text { Blepharocalyx salicifolius } \\
\text { (Kunth) O. Berg }\end{array}$ & Murta & Myrtaceae & $\mathrm{St}^{3}$ \\
\hline Cabralea canjerana (Vell.) Mart. & Canjerana & Meliaceae & $\mathrm{St}^{3}$ \\
\hline Calyptranthes concinna DC. & Guamirim & Myrtaceae & $S t^{5}$ \\
\hline $\begin{array}{l}\text { Campomanesia rhombea } \mathrm{O} \text {. } \\
\text { Berg }\end{array}$ & $\begin{array}{l}\text { Guabiroda- } \\
\text { folha-miúda }\end{array}$ & Myrtaceae & $\mathrm{St}^{10}$ \\
\hline $\begin{array}{l}\text { Campomanesia xanthocarpa O. } \\
\text { Berg }\end{array}$ & Guabiroba & Myrtaceae & $\mathrm{St}^{3}$ \\
\hline Casearia decandra Jacq. & Guaçatunga & Salicaceae & $S i^{4}$ \\
\hline Casearia obliqua Spreng. & Cambroé & Salicaceae & $\mathrm{Si}^{9}$ \\
\hline Cedrela fissilis Vell. & Cedro & Meliaceae & $\mathrm{St}^{2}$ \\
\hline Celtis iguanaea (Jacq.) Sarg. & $\begin{array}{l}\text { Esporão-de- } \\
\text { galo }\end{array}$ & $\begin{array}{l}\text { Cannabacea } \\
\text { e }\end{array}$ & $\mathrm{P}^{7}$ \\
\hline Cestrum intermedium Sendtn. & Coerana & Solanaceae & $\mathrm{Pi}^{10}$ \\
\hline $\begin{array}{l}\text { Cinnamomum amoenum } \\
\text { (Nees) Kosterm. }\end{array}$ & Canela & Lauraceae & $\mathrm{St}^{10}$ \\
\hline $\begin{array}{l}\text { Cinnamomum glaziovii (Mez) } \\
\text { Kosterm. }\end{array}$ & Canela-crespa & Lauraceae & $\mathrm{Cl}^{8}$ \\
\hline $\begin{array}{l}\text { Citharexylum myrianthum } \\
\text { Cham. }\end{array}$ & $\begin{array}{l}\text { Tarumã-de- } \\
\text { espinho }\end{array}$ & Verbenaceae & $\mathrm{Si}^{2}$ \\
\hline $\begin{array}{l}\text { Citronella gongonha (Mart.) R.A. } \\
\text { Howard }\end{array}$ & Congonha & $\begin{array}{l}\text { Cardiopterida } \\
\text { ceae }\end{array}$ & $\mathrm{St}^{10}$ \\
\hline Clethra uleana Sleumer & Canela-de-vaca & Clethraceae & $\mathrm{Si}^{10}$ \\
\hline $\begin{array}{l}\text { Coutarea hexandra (Jacq.) K. } \\
\text { Schum. }\end{array}$ & Quina & Rubiaceae & $\mathrm{Si}^{8}$ \\
\hline Cryptocarya aschersoniana Mez & Canela-fogo & Lauraceae & $C^{l 1}$ \\
\hline $\begin{array}{l}\text { Cryptocarya moschata Nees \& } \\
\text { C. Mart. }\end{array}$ & Canela-fogo & Lauraceae & $\mathrm{St}^{3}$ \\
\hline Cupania vernalis Cambess. & $\begin{array}{l}\text { Camboatá- } \\
\text { vermelho }\end{array}$ & Sapindaceae & $\mathrm{St}^{3}$ \\
\hline $\begin{array}{l}\text { Dalbergia frutescens (Vell.) } \\
\text { Britton }\end{array}$ & Rabo-de-bugio & Fabaceae & $\mathrm{Si}^{10}$ \\
\hline
\end{tabular}




\begin{tabular}{|c|c|c|c|}
\hline Nome Científico & Nome Popular & $\begin{array}{c}\text { Família } \\
\text { Botânica }\end{array}$ & $\begin{array}{c}\text { Grupo } \\
\text { Ecológico }\end{array}$ \\
\hline $\begin{array}{l}\text { Dasyphyllum spinescens (Less.) } \\
\text { Cabrera }\end{array}$ & Sucará & Asteraceae & $\mathrm{Pi}^{4}$ \\
\hline $\begin{array}{l}\text { Dasyphyllum tomentosum } \\
\text { (Spreng.) Cabrera }\end{array}$ & Sucará-piloso & Asteraceae & $\mathrm{Pi}^{10}$ \\
\hline Dicksonia sellowiana Hook. & Xaxim & $\begin{array}{l}\text { Dicksoniacea } \\
\text { e }\end{array}$ & $\mathrm{Cl}^{4}$ \\
\hline Duranta vestita Cham. & Duranta & Verbenaceae & $\mathrm{Pi}^{10}$ \\
\hline Eugenia involucrata DC. & $\begin{array}{l}\text { Cerejeira-do- } \\
\text { mato }\end{array}$ & Myrtaceae & $\mathrm{Cl}^{4}$ \\
\hline Eugenia pluriflora DC. & Guamirim & Myrtaceae & $\mathrm{Cl}^{10}$ \\
\hline Eugenia psidififlora O. Berg & Guamirim & Myrtaceae & $\mathrm{Cl}^{10}$ \\
\hline Eugenia subterminalis DC. & Guamirim & Myrtaceae & $\mathrm{Cl}^{10}$ \\
\hline $\begin{array}{l}\text { Eugenia uruguayensis } \\
\text { Cambess. }\end{array}$ & $\begin{array}{l}\text { Batinga- } \\
\text { vermelha }\end{array}$ & Myrtaceae & $\mathrm{St}^{4}$ \\
\hline $\begin{array}{l}\text { Gordonia acutifolia (Wawra) H. } \\
\text { Keng }\end{array}$ & Gordonia & Theaceae & $\mathrm{Si}^{10}$ \\
\hline Guapira opposita (Vell.) Reitz & Maria-faceira & $\begin{array}{l}\text { Nyctaginacea } \\
\mathrm{e}\end{array}$ & $\mathrm{St}^{8}$ \\
\hline $\begin{array}{l}\text { Handroanthus heptaphyllus } \\
\text { (Vell.) Mattos }\end{array}$ & Ipê-roxo & Bignoniaceae & $\mathrm{St}^{2}$ \\
\hline $\begin{array}{l}\text { Hennecartia omphalandra J. } \\
\text { Poiss. }\end{array}$ & Canema & Monimiaceae & $\mathrm{Cl}^{3}$ \\
\hline Ilex brevicuspis Reissek & Caúna & Aquifoliaceae & $\mathrm{St}^{10}$ \\
\hline Ilex dumosa Reissek & Caúna & Aquifoliaceae & $\mathrm{St}^{10}$ \\
\hline llex microdonta Reissek & Caúna & Aquifoliaceae & $\mathrm{St}^{10}$ \\
\hline Ilex paraguariensis A. St.-Hil & Erva-mate & Aquifoliaceae & $\mathrm{St}^{9}$ \\
\hline Ilex theezans Mart. Ex Reissek & Caúna & Aquifoliaceae & $\mathrm{St}^{6}$ \\
\hline Inga vera Kunth & Ingá-banana & Fabaceae & $\mathrm{Si}^{10}$ \\
\hline Lamanonia ternata Vell. & Guaperê & Cunoniaceae & $\mathrm{Si}^{2}$ \\
\hline $\begin{array}{l}\text { Laplacea acutifolia (Wawra) } \\
\text { Kobuski }\end{array}$ & $\begin{array}{l}\text { Pau-de-santa- } \\
\text { Rita }\end{array}$ & Theaceae & $\mathrm{Pi}^{10}$ \\
\hline Lithraea brasiliensis Marchand & Aroeira-brava & $\begin{array}{l}\text { Anacardiacea } \\
\mathrm{e}\end{array}$ & $\mathrm{Pi}^{4}$ \\
\hline $\begin{array}{l}\text { Lonchocarpus campestris Mart. } \\
\text { ex Benth. }\end{array}$ & Rabo-de-bugio & Fabaceae & $\mathrm{Pi}^{1}$ \\
\hline $\begin{array}{l}\text { Lonchocarpus nitidus (Vogel) } \\
\text { Benth. }\end{array}$ & Rabo-de-bugio & Fabaceae & $\mathrm{Pi}^{10}$ \\
\hline Luehea divaricata Mart. & Açoita-cavalo & Malvaceae & $\mathrm{St}^{2}$ \\
\hline $\begin{array}{l}\text { Machaerium paraguariense } \\
\text { Hassl. }\end{array}$ & Canela-do-brejo & Fabaceae & $\mathrm{St}^{10}$ \\
\hline $\begin{array}{l}\text { Machaerium stipitatum (DC.) } \\
\text { Vogel }\end{array}$ & Farinha & Fabaceae & $\mathrm{Si}^{9}$ \\
\hline Matayba elaeagnoides Radlk. & Miguel-pintado & Sapindaceae & $\mathrm{St}^{3}$ \\
\hline
\end{tabular}




\begin{tabular}{|c|c|c|c|}
\hline Nome Científico & Nome Popular & $\begin{array}{c}\text { Família } \\
\text { Botânica }\end{array}$ & $\begin{array}{c}\text { Grupo } \\
\text { Ecológico }\end{array}$ \\
\hline Maytenus evonymoides Reissek & $\begin{array}{l}\text { Coração-de- } \\
\text { bugre }\end{array}$ & Celastraceae & $\mathrm{Cl}^{10}$ \\
\hline Miconia cinerascens Miq. & Pixirica & $\begin{array}{l}\text { Melastomata } \\
\text { ceae }\end{array}$ & $\mathrm{Si}^{10}$ \\
\hline $\begin{array}{l}\text { Myrceugenia foveolata D. } \\
\text { Legrand }\end{array}$ & Guamirim & Myrtaceae & $\mathrm{St}^{10}$ \\
\hline $\begin{array}{l}\text { Myrceugenia cucullata D. } \\
\text { Legrand }\end{array}$ & Guamirim & Myrtaceae & $\mathrm{Cl}^{4}$ \\
\hline $\begin{array}{l}\text { Myrceugenia glaucescens } \\
\text { (Cambess.) D. Legrand \& } \\
\text { Kausel }\end{array}$ & Guamirim & Myrtaceae & $\mathrm{St}^{10}$ \\
\hline $\begin{array}{l}\text { Myrceugenia miersiana } \\
\text { (Gardner) D. Legrand \& Kause }\end{array}$ & $\begin{array}{l}\text { Guamirim- } \\
\text { piloso }\end{array}$ & Myrtaceae & $\mathrm{Cl}^{4}$ \\
\hline $\begin{array}{l}\text { Myrceugenia myrcioides } \\
\text { (Cambess.) O. Berg }\end{array}$ & Guamirim & Myrtaceae & $\mathrm{Cl}^{10}$ \\
\hline $\begin{array}{l}\text { Myrceugenia oxysepala (Burret) } \\
\text { D. Legrand \& Kausel }\end{array}$ & Guamirim & Myrtaceae & $\mathrm{St}^{10}$ \\
\hline $\begin{array}{l}\text { Myrcia bombycina (O. Berg) } \\
\text { Kiaersk. }\end{array}$ & Guamirim & Myrtaceae & $\mathrm{Cl}^{10}$ \\
\hline Myrcia oligantha O. Berg & Guamirim & Myrtaceae & $\mathrm{Cl}^{4}$ \\
\hline $\begin{array}{l}\text { Myrcianthes gigantea } \\
\text { (Cambess.) O. Berg }\end{array}$ & Araçá-do-mato & Myrtaceae & $\mathrm{St}^{4}$ \\
\hline $\begin{array}{l}\text { Myrcianthes pungens (O. Berg) } \\
\text { D. Legrand }\end{array}$ & Guabiju & Myrtaceae & $\mathrm{St}^{1}$ \\
\hline $\begin{array}{l}\text { Myrciaria delicatula (DC.) O. } \\
\text { Berg }\end{array}$ & Camboim & Myrtaceae & $\mathrm{Cl}^{4}$ \\
\hline $\begin{array}{l}\text { Myrciaria floribunda (H. West ex } \\
\text { Willd.) O. Berg }\end{array}$ & Camboim & Myrtaceae & $\mathrm{Cl}^{4}$ \\
\hline Myrciaria tenella (DC.) O. Berg & Camboinzinho & Myrtaceae & $\mathrm{Cl}^{4}$ \\
\hline $\begin{array}{l}\text { Myrrhinium atropurpureum } \\
\text { Schott }\end{array}$ & Murtilho & Myrtaceae & $\mathrm{St}^{4}$ \\
\hline $\begin{array}{l}\text { Myrsine coriacea(Sw.) R. Br. ex } \\
\text { Roem. \& Schult }\end{array}$ & Capororoca & Primulaceae & $\mathrm{Pi}^{7}$ \\
\hline $\begin{array}{l}\text { Myrsine laetevirens (Mez) } \\
\text { Arechav. }\end{array}$ & Capororoca & Primulaceae & $\mathrm{Pi}^{10}$ \\
\hline $\begin{array}{l}\text { Myrsine lorentziana (Mez) } \\
\text { Arechav. }\end{array}$ & Capororoca & Primulaceae & $\mathrm{Pi}^{10}$ \\
\hline Myrsine umbellata Mart. & Capororocão & Primulaceae & $\mathrm{Si}^{1}$ \\
\hline $\begin{array}{l}\text { Nectandra } \\
\text { megapotamica(Spreng.) Mez }\end{array}$ & Canela-preta & Lauraceae & $\mathrm{St}^{3}$ \\
\hline $\begin{array}{l}\text { Ocotea indecora Schott ex } \\
\text { Meissner }\end{array}$ & Canela & Lauraceae & $\mathrm{St}^{9}$ \\
\hline $\begin{array}{l}\text { Ocotea porosa (Nees \& Mart.) } \\
\text { Barroso }\end{array}$ & Imbuia & Lauraceae & $\mathrm{Cl}^{2}$ \\
\hline Ocotea puberula (Rich.) Nees & Canela-guaicá & Lauraceae & $\mathrm{St}^{9}$ \\
\hline Ocotea pulchella Mart. & Canela-lajeana & Lauraceae & $\mathrm{St}^{3}$ \\
\hline
\end{tabular}




\begin{tabular}{|c|c|c|c|}
\hline Nome Científico & Nome Popular & $\begin{array}{l}\text { Família } \\
\text { Botânica }\end{array}$ & $\begin{array}{c}\text { Grupo } \\
\text { Ecológico }\end{array}$ \\
\hline Oreopanax fulvus Marchal & Tamanqueira & Araliaceae & $\mathrm{Cl}^{10}$ \\
\hline Picramnia parvifolia Engl. & Pau-amargo & $\begin{array}{l}\text { Picramniacea } \\
\text { e }\end{array}$ & $\mathrm{St}^{4}$ \\
\hline Pilocarpus pennatifolius Lem. & Jaborandi & Rutaceae & $\mathrm{Cl}^{5}$ \\
\hline $\begin{array}{l}\text { Piptocarpha notata (Less.) } \\
\text { Baker }\end{array}$ & Canela-podre & Asteraceae & $\mathrm{Pi}^{10}$ \\
\hline $\begin{array}{l}\text { Podocarpus lambertii Klotzsch } \\
\text { ex Endl. }\end{array}$ & Pinheiro-bravo & $\begin{array}{l}\text { Podocarpace } \\
\text { ae }\end{array}$ & $\mathrm{St}^{2}$ \\
\hline Prunus myrtifolia (L.) Urb. & $\begin{array}{l}\text { Pessegueiro- } \\
\text { bravo }\end{array}$ & Rosaceae & $S i^{6}$ \\
\hline Rhamnus sphaerosperma Sw. & Cangica & Rhamnaceae & $\mathrm{Si}^{10}$ \\
\hline Roupala montana Aubl. & $\begin{array}{l}\text { Carvalho- } \\
\text { brasileiro }\end{array}$ & Proteaceae & $C^{14}$ \\
\hline $\begin{array}{l}\text { Sapium glandulosum (L.) } \\
\text { Morong }\end{array}$ & Pau-leiteiro & $\begin{array}{l}\text { Euphorbiacea } \\
\text { e }\end{array}$ & $S i^{5}$ \\
\hline Scutia buxifolia Reissek & Coronilha & Rhamnaceae & $S i^{5}$ \\
\hline Sebastiania brasiliensis Spreng. & $\begin{array}{l}\text { Branquilho- } \\
\text { leiteiro }\end{array}$ & $\begin{array}{l}\text { Euphorbiacea } \\
\text { e }\end{array}$ & $S t^{4}$ \\
\hline $\begin{array}{l}\text { Sebastiania commersoniana } \\
\text { (Baill.) L.B. Sm. \& Downs }\end{array}$ & Branquilho & $\begin{array}{l}\text { Euphorbiacea } \\
\text { e }\end{array}$ & $\mathrm{Si}^{2}$ \\
\hline Seguieria aculeata Jacq. & $\begin{array}{l}\text { Limoeiro-do- } \\
\text { mato }\end{array}$ & $\begin{array}{l}\text { Phytolaccace } \\
\text { ae }\end{array}$ & $\mathrm{Si}^{10}$ \\
\hline Siphoneugena reitzii D. Legrand & Camboim & Myrtaceae & $\mathrm{St}^{5}$ \\
\hline Sloanea monosperma Vell. & Sapopema & $\begin{array}{l}\text { Elaeocarpace } \\
\text { ae }\end{array}$ & $\mathrm{St}^{3}$ \\
\hline $\begin{array}{l}\text { Solanum pabstii L.B. Sm. \& } \\
\text { Downs }\end{array}$ & Canema & Solanaceae & $\mathrm{Pi}^{10}$ \\
\hline Solanum pseudocapsicum L. & Quineira & Solanaceae & $\mathrm{Pi}^{10}$ \\
\hline Solanum pseudoquina A. St.-Hil. & Peloteira & Solanaceae & $\mathrm{Pi}^{1}$ \\
\hline $\begin{array}{l}\text { Solanum sanctaecatharinae } \\
\text { Dunal }\end{array}$ & Joá-manso & Solanaceae & $\mathrm{Pi}^{4}$ \\
\hline $\begin{array}{l}\text { Strychnos brasiliensis (Spreng.) } \\
\text { Mart. }\end{array}$ & Anzol-de-lontra & Loganiaceae & $\mathrm{Pi}^{1}$ \\
\hline Styrax leprosus Hook. \& Arn. & Carne-de-vaca & Styracaceae & $\mathrm{St}^{6}$ \\
\hline $\begin{array}{l}\text { Syagrus romanzoffiana (Cham.) } \\
\text { Glassman }\end{array}$ & Jerivá & Arecaceae & $\mathrm{Si}^{2}$ \\
\hline Symplocos pentandra Occhioni & Sete-sangrias & $\begin{array}{l}\text { Symplocacea } \\
\text { e }\end{array}$ & $\mathrm{St}^{9}$ \\
\hline Symplocos tetrandra Mart. & Sete-sangrias & $\begin{array}{l}\text { Symplocacea } \\
\text { e }\end{array}$ & $\mathrm{St}^{9}$ \\
\hline $\begin{array}{l}\text { Symplocos uniflora (Pohl) } \\
\text { Benth. }\end{array}$ & Sete-sangrias & $\begin{array}{l}\text { Symplocacea } \\
\text { e }\end{array}$ & $\mathrm{Si}^{2}$ \\
\hline $\begin{array}{l}\text { Tabernaemontana catharinensis } \\
\text { A. DC. }\end{array}$ & $\begin{array}{l}\text { Jasmim- } \\
\text { catavento }\end{array}$ & Apocynaceae & $\mathrm{Si}^{10}$ \\
\hline
\end{tabular}




\begin{tabular}{lllc}
\hline \multicolumn{1}{c}{ Nome Científico } & Nome Popular & $\begin{array}{c}\text { Família } \\
\text { Botânica }\end{array}$ & $\begin{array}{c}\text { Grupo } \\
\text { Ecológico }\end{array}$ \\
\hline $\begin{array}{l}\text { Vernonanthura discolor } \\
\text { (Spreng.) H. Rob. }\end{array}$ & $\begin{array}{l}\text { Vassourão- } \\
\text { branco }\end{array}$ & Asteraceae & $\mathrm{Pi}^{6}$ \\
\hline $\begin{array}{l}\text { Weinmannia paulliniifolia Pohl } \\
\begin{array}{l}\text { Xylosma pseudosalzmanii } \\
\text { Sleumer }\end{array}\end{array}$ & Gramimunha & Cunoniaceae & $\mathrm{Si}^{10}$ \\
\hline $\begin{array}{l}\text { Xylosma tweediana (Clos) } \\
\text { Eichler }\end{array}$ & Sucará & Salicaceae & $\mathrm{Si}^{4}$ \\
\hline Zanthoxylum fagara (L.) Sarg. & $\begin{array}{l}\text { Mamica-de- } \\
\text { cadela }\end{array}$ & Rutaceae & $\mathrm{Si}^{10}$ \\
\hline $\begin{array}{l}\text { Zanthoxylum kleinii(R.S. } \\
\text { Cowan) P.G. Waterman }\end{array}$ & $\begin{array}{l}\text { Mamica-de- } \\
\text { cadela }\end{array}$ & Rutaceae & $\mathrm{Si}^{4}$ \\
\hline $\begin{array}{l}\text { Zanthoxylum petiolare A. St.-Hil. } \\
\text { \& Tul. }\end{array}$ & $\begin{array}{l}\text { Mamica-de- } \\
\text { cadela }\end{array}$ & Rutaceae & $\mathrm{Si}^{10}$ \\
\hline Zanthoxylum rhoifolium Lam. & $\begin{array}{l}\text { Mamica-de- } \\
\text { cadela }\end{array}$ & Rutaceae & $\mathrm{Si}^{3}$ \\
\hline
\end{tabular}

Onde: Pi - espécie pioneira; Si - secundária inicial; St - secundária tardia; Cl - Climácica; ${ }^{1}$ Vaccaro(2002); ${ }^{2}$ Carvalho (2003); ${ }^{3}$ Carvalho (2006); ${ }^{4}$ Moscovich (2006); ${ }^{5}$ Rio Grande do Sul (2007); ${ }^{6}$ Carvalho (2008); ${ }^{7}$ Stepka (2008); ${ }^{8}$ Lorenzi (2008); ${ }^{9}$ Sawckzuk (2009); ${ }^{10}$ classificação sugerida pelo autor.

Conforme os dados levantados pelo Inventário Florestal Contínuo do Rio Grande do Sul, foram encontrados em toda região da Floresta com Araucária 246 espécies, pertencentes a 58 famílias botânicas (RIO GRANDE DO SUL, 2002). No entanto, considerando o conjunto dos 10 anos amostrados na área de estudo, foram encontradas 117 espécies arbóreas, 75 gêneros e 44 famílias botânicas, semelhante ao encontrado por MOSCOVICH (2006), no município de Nova Prata, RS. Atribui-se a semelhante riqueza florística entre ambos locais devido as similares características ecológicas, essencialmente à configuração fitogeográfica e isolamento dos locais às intervenções antrópicas.

Relacionando o presente estudo com demais realizados na mesma região fitogeográfica, a Flona de São Francisco de Paula mostrou-se com maior riqueza de espécies. Corroborando com o exposto, HERRERA et al. (2009) determinaram 71 espécies, 54 gêneros e 33 famílias botânicas na reserva florestal da EMBRAPA/EPAGRI em Caçador, SC. Outro estudo realizado em São João do Triunfo, PR, descreveu 69 espécies, distribuídas em 44 gêneros e incluídos em 29 famílias (DURIGAN, 1999).

Com relação ao número de espécies que apresentaram valor de densidade inferior a 1 ind/ha e, por esse motivo, consideradas raras no ambiente (KAGEYAMA \& GANDARA, 1994), foram descritas 49 espécies raras no ano de 2000. No ano de 2009, este número baixou para 48 espécies. Com relação a esta observação, ressalvam-se duas importantes considerações: a primeira refere-se à classificação das espécies raras, as quais, em sua maioria, enquadram-se como pioneiras ou secundárias iniciais, representadas por gêneros como Solanun, Myrsine, Clethra, Zanthoxylum, Citharexylum, entre outros, que se caracterizam por serem espécies oportunistas, exigentes de luz, mantendo-se entre a transição do ambiente heliófilo em ombrófilo, encerrando assim seu ciclo.

A segunda consideração diz respeito à região de ocorrência de espécies que, em alguns casos, determina sua menor abundância em locais que não apresentam 
condições ótimas para seu desenvolvimento. A exemplo, toma-se a espécie $H$. heptaphyllus (Ipê-roxo) que, como sugerido por SOBRAL et al. (2006), tem sua ocorrência na depressão central do estado do Rio Grande do Sul e na floresta do Alto Uruguai, conferindo sua baixa abundância no local de estudo, por esta não configurar seu ótimo ecológico.

O presente estudo difere dos realizados por SAWCZUK (2009) e DURIGAN (1999) com relação à dinâmica do recrutamento de novas espécies, onde os autores supracitados citam respectivamente o recrutamento de cinco novas espécies em seis anos e o recrutamento de uma nova espécie em um período de três anos. Para a Flona de são Francisco de Paula, não foi verificado o recrutamento de novas espécies ao longo do período inventariado. Em contrapartida, ocorreu à supressão de seis espécies no mesmo período, sendo que destas, duas espécies são classificadas como pioneiras ( $P$. notata e $S$. pseudocapsicum) e secundárias iniciais ( $R$. sphaerosperma e G.acutifolia), e duas são secundárias tardias ( $S$. pentandra e $G$. opposita), fato normal na dinâmica da floresta, onde a redução de luminosidade decorrente do crescimento propicia a mortalidade dos grupos ecológicos iniciais (BUDOWSKI, 1965).

Considerando os gêneros botânicos, Myrceugenia foi o mais representativo em termos florísticos, abrangendo sete espécies. Os gêneros Eugenia, Ilex, Myrsine e Solanum foram representados por cinco espécies cada. Ocotea e Zanthoxylum, quatro espécies; Lonchocarpus, Myrciaria, Symplocos, três espécies; Annona, Banara, Campomanesia, Casearia, Cestrum, Cinnamomum, Cryptocarya, Dasyphillum, Inga, Machaerium, Myrcia, Myrcianthes, Sebastiania, Xylosma com duas espécies cada. Os demais gêneros apresentaram uma única espécie.

Nota-se o predomínio de 11 famílias botânicas na área de estudo. A família Myrtaceae apresentou maior riqueza, com 10 gêneros e 25 espécies, correspondendo a $22 \%$ do número de espécies e $25 \%$ do número total de indivíduos (QUADRO3). As famílias Lauraceae, Salicaceae, Asteraceae, Sapindaceae, Solanaceae, Rutaceae, Symplocaceae e Euphorbiaceae, representam juntas 60,3\% do total de espécies da floresta e $62,3 \%$ do total de indivíduos.

QUADRO 3 - Análise da representatividade de famílias botânicas entre diferentes estudos desenvolvidos na Floresta de Araucária

\begin{tabular}{|c|c|c|c|c|c|c|c|}
\hline \multicolumn{2}{|c|}{ Presente estudo } & \multicolumn{2}{|c|}{ Moscovich (2006) } & \multicolumn{2}{|c|}{$\begin{array}{l}\text { Herrera et al. } \\
(2009)\end{array}$} & \multicolumn{2}{|c|}{ Sawczuk (2009) } \\
\hline Família & Espécie & Família & Espécie & Família & Espécie & Família & Espécie \\
\hline Myrtaceae & 22 & Myrtaceae & 23 & $\begin{array}{c}\text { Myrtacea } \\
\text { e }\end{array}$ & 14 & $\begin{array}{c}\text { Myrtacea } \\
\text { e }\end{array}$ & 17 \\
\hline Lauraceae & 9 & Lauraceae & 8 & Fabaceae & 5 & $\begin{array}{c}\text { Lauracea } \\
\text { e }\end{array}$ & 13 \\
\hline Fabaceae & 8 & $\begin{array}{l}\text { Aquifoliac } \\
\text { eae }\end{array}$ & 6 & $\begin{array}{c}\text { Lauracea } \\
\text { e }\end{array}$ & 5 & $\begin{array}{l}\text { Salicace } \\
\text { ae }\end{array}$ & 8 \\
\hline Salicaceae & 6 & $\begin{array}{l}\text { Euphorbia } \\
\text { ceae }\end{array}$ & 5 & $\begin{array}{c}\text { Asterace } \\
\text { ae }\end{array}$ & 4 & $\begin{array}{c}\text { Sapindac } \\
\text { eae }\end{array}$ & 5 \\
\hline Solanaceae & 6 & $\begin{array}{c}\text { Sapindace } \\
\text { ae }\end{array}$ & 5 & $\begin{array}{c}\text { Salicacea } \\
\text { e }\end{array}$ & 4 & $\begin{array}{l}\text { Rubiace } \\
\text { ae }\end{array}$ & 5 \\
\hline $\begin{array}{c}\text { Aquifoliace } \\
\text { ae }\end{array}$ & 5 & $\begin{array}{c}\text { Salicacea } \\
\mathrm{e}\end{array}$ & 5 & $\begin{array}{c}\text { Aquifoliac } \\
\text { eae }\end{array}$ & 3 & $\begin{array}{c}\text { Asterace } \\
\text { ae }\end{array}$ & 4 \\
\hline Total (\%) & 50 & & 45 & & 49 & & 45 \\
\hline
\end{tabular}


KLEIN (1960) descreveu a ocorrência de mais de 50 espécies da família Myrtaceae na Floresta com Araucária, verificando a elevada adaptabilidade dessa família tanto no estrato superior como no sub-bosque (LONGHI et al., 2008). Lauraceae foi à segunda família mais característica da floresta, corroborando com os demais trabalhos, na qual foram encontradas entre cinco e 13 espécies. As famílias Fabaceae e Salicaceae mostraram-se como a terceira e quarta mais representativas, sendo que estas posições não se confirmam nos demais trabalhos pesquisados, o que pode ser atribuído a características autoecológicas das espécies.

A família Araucariaceae apresenta apenas uma espécie, porém elevada abundância, em que $A$. angustifolia apresentou $12,1 \%$ do número total de indivíduos. Estas análises evidenciam as observações de KLEIN (1960) que caracteriza a região fitogeográfica como heterogênea, formada por diferentes associações florísticas, mantendo $A$. angustifolia como espécie mais característica.

Por meio da análise das cinco famílias de maior Valor de Importância (VI) entre os anos de 2000 a 2009 (Tabela 1), observa-se que Myrtaceae manteve o maior valor, e mesmo apresentando dominância relativa amplamente inferior a da família Araucariaceae, apresentou alta densidade relativa.

TABELA 1 - Análise estrutural das cinco principais famílias botânicas entre os anos de 2000 a 2009

\begin{tabular}{lcccccccc}
\hline \multirow{1}{*}{ Família } & \multicolumn{2}{c}{ DR } & \multicolumn{2}{c}{ FR } & \multicolumn{2}{c}{ DoR } & \multicolumn{2}{c}{ VI (\%) } \\
\cline { 2 - 9 } & $\mathbf{2 0 0 0}$ & $\mathbf{2 0 0 9}$ & $\mathbf{2 0 0 0}$ & $\mathbf{2 0 0 9}$ & $\mathbf{2 0 0 0}$ & $\mathbf{2 0 0 9}$ & $\mathbf{2 0 0 0}$ & $\mathbf{2 0 0 9}$ \\
\hline Myrtaceae & 26,1 & 25,2 & 27,4 & 26,5 & 16,2 & 15,8 & 23,2 & 22,5 \\
Araucariaceae & 12,6 & 12,3 & 8,0 & 8,0 & 33,4 & 35,9 & 18,0 & 18,8 \\
Lauraceae & 11,0 & 11,5 & 12,2 & 12,7 & 14,3 & 14,3 & 12,4 & 12,8 \\
Aquifoliaceae & 10,3 & 10,9 & 10,3 & 10,6 & 10,4 & 10,6 & 10,3 & 10,7 \\
Euphorbiaceae & 10,5 & 9,7 & 9,0 & 8,8 & 6,5 & 5,76 & 8,7 & 8,1 \\
\hline
\end{tabular}

DR: Densidade Relativa; FR: Frequência Relativa; DoR: Dominância Relativa; VI: Valor de Importância (0-100\%).

A dinâmica observada entre as famílias botânicas não proporcionou alterações na ordem de importância destas. Porém, observa-se a supressão de indivíduos da família Myrtaceae, ocorrendo uma redução na densidade; o mesmo foi observado para as famílias Araucariaceae e Euphorbiaceae. Já as famílias Lauraceae e Aquifoliaceae apresentaram aumento relativo de seus indivíduos na floresta. Quanto à dominância relativa, Myrtaceae apresentou redução em seu valor, perdendo área transversal na floresta. Todavia, Araucariaceae, mesmo reduzindo sua representatividade em densidade de indivíduos, aumentou sua área transversal, verificando-se uma substituição quantitativa (número de indivíduos) por qualitativa (área transversal).

De modo geral, a floresta caracteriza-se pela maior representatividade do grupo ecológico secundário tardio, representando aproximadamente $51 \%$ do número total de indivíduos (Figura 1). O grupo das espécies secundárias iniciais e climáxicas apresentaram $22 \%$ e $20,5 \%$ do total, respectivamente. O grupo das pioneiras correspondeu a $6,5 \%$ do total. Portanto, houve o predomínio de espécies com características ombrófilas, tendência que deve acompanhar o processo de seneiscência da floresta até atingir a "sere" clímax, onde a presença de espécies de estágios iniciais ficará limitada a dinâmica da abertura de clareiras (HARTSHORN, 1978). 


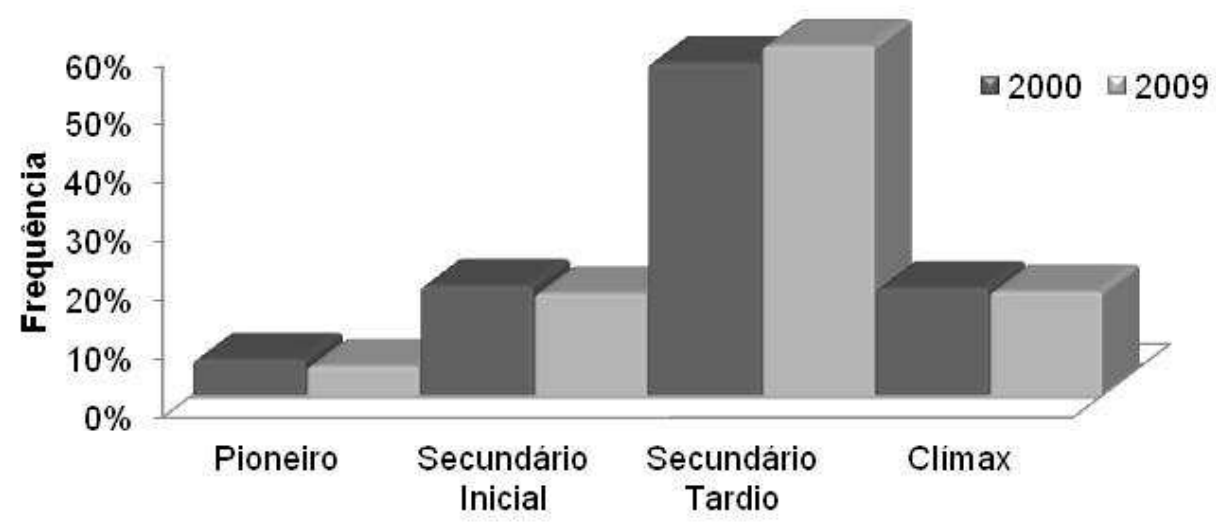

FIGURA 1 - Frequência do número de indivíduos nos grupos ecológicos entre os anos de 2000 a 2009

Avaliando a dinâmica quanto à porcentagem de indivíduos em seus respectivos grupos ecológicos, observam-se pequenas alterações na frequência, como a redução de $1 \%$ das espécies pioneiras e secundárias iniciais, o aumento de $2 \%$ das espécies secundárias tardias e redução de $1 \%$ das climáxicas. As espécies com maior densidade dentro de cada grupo foram: P. lambertii, com $16 \%$ do total da densidade do grupo das pioneiras; $C$. decandra, totalizando $29,7 \%$ no grupo das secundárias iniciais; I. brevicuspis, com $12,8 \%$ do grupo das secundárias tardias e $C$. aschersoniana, com $19,2 \%$ no grupo das climáxicas.

Com relação à distribuição da frequência de indivíduos em classes diamétricas, foram descritas 21 classes, sendo a última classe aberta, abrangendo os diâmetros iguais ou superiores a 109,5 cm (Figura 2).

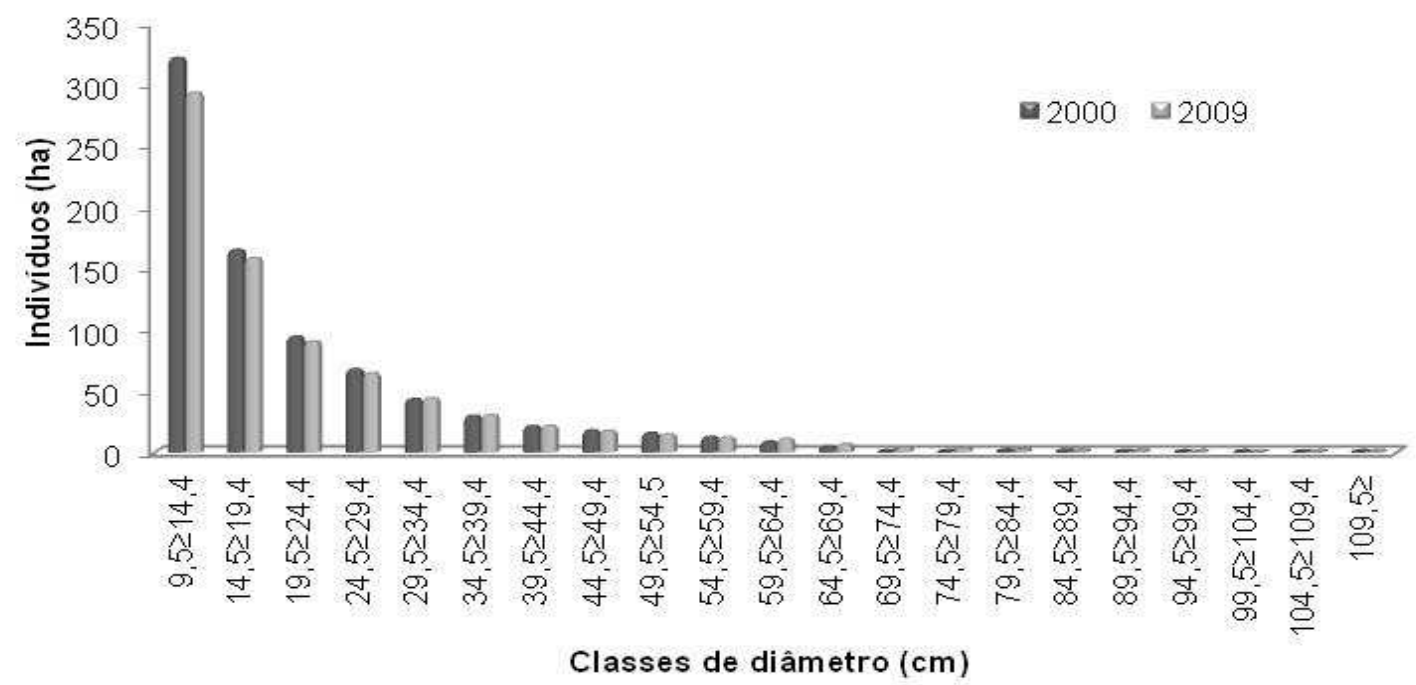

FIGURA 2 - Distribuição em classes diamétricas da comunidade arbórea nos anos de 2000 e 2009

Observa-se redução da frequência de indivíduos à medida que ocorre o aumento diamétrico, configurando uma distribuição exponencial negativa, estrutura típica de florestas naturais balanceadas não alteradas com capacidade autoregenerativa. Seguindo o observado pela estrutura diamétrica, CHAMI et al., (2011), por meio da análise de plântulas e dispersão de sementes na 
também verificaram a capacidade de regeneração da floresta.

As observações referentes à estrutura horizontal, que avalia o estoque em crescimento e a participação de cada espécie na comunidade, foi realizada para os anos de 2000 e 2009, limitadas somente para as espécies com densidade relativa superior a 1\%, conforme as Tabela 2 e 3.

TABELA 2. Estrutura Horizontal referente ao ano de 2000

\begin{tabular}{|c|c|c|c|c|c|c|c|c|}
\hline Nome Científico & DA & DR & FA & FR & DoA & DoR & VC (\%) & VI (\%) \\
\hline Araucaria angustifolia & 103,42 & 12,63 & 44,06 & 7,96 & 14,12 & 33,40 & 23,01 & 18,00 \\
\hline Ilex brevicuspis & 45,57 & 5,57 & 27,57 & 4,98 & 3,19 & 7,55 & 6,56 & 6,03 \\
\hline Blepharocalyx salicifolius & 43,36 & 5,30 & 30,38 & 5,49 & 2,95 & 6,99 & 6,14 & 5,92 \\
\hline $\begin{array}{l}\text { Cryptocarya } \\
\text { aschersoniana }\end{array}$ & 28,17 & 3,44 & 17,00 & 3,07 & 2,14 & 5,06 & 4,25 & 3,86 \\
\hline $\begin{array}{l}\text { Sebastiania } \\
\text { commersoniana }\end{array}$ & 34,11 & 4,17 & 16,00 & 2,89 & 1,78 & 4,21 & 4,19 & 3,76 \\
\hline Casearia decandra & 35,21 & 4,30 & 28,47 & 5,14 & 0,49 & 1,17 & 2,73 & 3,54 \\
\hline Sebastiania brasiliensis & 39,74 & 4,85 & 25,35 & 4,58 & 0,49 & 1,17 & 3,01 & 3,53 \\
\hline Ilex paraguariensis & 31,99 & 3,91 & 24,04 & 4,34 & 0,87 & 2,06 & 2,98 & 3,44 \\
\hline Siphoneugena reitzii & 27,57 & 3,37 & 15,29 & 2,76 & 0,89 & 2,12 & 2,74 & 2,75 \\
\hline Ocotea pulchella & 18,91 & 2,31 & 16,00 & 2,89 & 1,23 & 2,90 & 2,61 & 2,70 \\
\hline Eugenia psidiiflora & 25,96 & 3,17 & 16,50 & 2,98 & 0,47 & 1,11 & 2,14 & 2,42 \\
\hline Nectandra megapotamica & 17,91 & 2,19 & 14,69 & 2,65 & 0,98 & 2,33 & 2,26 & 2,39 \\
\hline Eugenia uruguayensis & 20,62 & 2,52 & 14,49 & 2,62 & 0,57 & 1,35 & 1,94 & 2,16 \\
\hline Myrceugenia cucullata & 18,61 & 2,27 & 14,08 & 2,54 & 0,31 & 0,74 & 1,50 & 1,85 \\
\hline Lamanonia ternata & 13,08 & 1,60 & 10,66 & 1,93 & 0,82 & 1,94 & 1,77 & 1,82 \\
\hline Podocarpus lambertii & 13,78 & 1,68 & 9,26 & 1,67 & 0,83 & 1,96 & 1,82 & 1,77 \\
\hline Dicksonia sellowiana & 15,69 & 1,92 & 8,95 & 1,62 & 0,68 & 1,60 & 1,76 & 1,71 \\
\hline Ocotea puberula & 11,67 & 1,43 & 8,35 & 1,51 & 0,84 & 1,99 & 1,71 & 1,64 \\
\hline Campomanesia rhombea & 14,19 & 1,73 & 10,76 & 1,95 & 0,37 & 0,87 & 1,30 & 1,52 \\
\hline Matayba elaeagnoides & 13,48 & 1,65 & 9,56 & 1,73 & 0,50 & 1,18 & 1,41 & 1,52 \\
\hline Sapium glandulosum & 11,87 & 1,45 & 8,65 & 1,56 & 0,47 & 1,10 & 1,27 & 1,37 \\
\hline $\begin{array}{l}\text { Campomanesia } \\
\text { xanthocarpa } \\
\end{array}$ & 12,37 & 1,51 & 8,75 & 1,58 & 0,34 & 0,81 & 1,16 & 1,30 \\
\hline Roupala brasiliensis & 10,16 & 1,24 & 8,05 & 1,45 & 0,34 & 0,80 & 1,02 & 1,17 \\
\hline Luehea divaricata & 11,67 & 1,43 & 5,84 & 1,05 & 0,42 & 1,00 & 1,21 & 1,16 \\
\hline Subtotal 1 & 648,69 & 79,26 & 415,29 & 75,02 & 38,33 & 90,71 & 84,93 & 81,65 \\
\hline Subtotal 2 & 184,92 & 22,52 & 149,32 & 27,04 & 5,06 & 11,95 & 17,28 & 20,46 \\
\hline Total & 818,81 & 100 & 553,42 & 100 & 42,27 & 100 & 100 & 100 \\
\hline
\end{tabular}

Onde: DA- Densidade Absoluta (ind/ha); DR- Densidade Relativa (\%); FAFrequência Absoluta; FR- Frequência Relativa (\%); DoA-Dominância Absoluta $\left(\mathrm{m}^{2} / \mathrm{ha}\right)$; DoR- Dominância Relativa (\%); VC- Valor de cobertura (0-100\%); VI- Valor de Importância (0-100\%). 
TABELA 3 - Estrutura Horizontal referente ao ano de 2009

\begin{tabular}{|c|c|c|c|c|c|c|c|c|}
\hline Nome Científico & DA & DR & FA & $\mathbf{F R}$ & OA & DoR & $\begin{array}{l}\text { VC } \\
(\%) \\
\end{array}$ & $\begin{array}{c}\mathrm{VI} \\
(\%) \\
\end{array}$ \\
\hline Araucaria angustifolia & 6,68 & 2,27 & 44,02 & 8,23 & 6,81 & 5,95 & 24,11 & 18,82 \\
\hline $\begin{array}{l}\text { Blephar } \\
\text { salicifoli }\end{array}$ & 41,31 & 5,24 & 29,35 & 5,49 & 3,57 & 7,62 & 6,43 & 6,12 \\
\hline ex brevicuspis & 4,32 & 5,63 & 26,93 & 5,04 & 3,53 & 7,55 & 6,59 & 6,07 \\
\hline Casearia d &, 63 & 92 & 2,86 & 15 & 65 & 38 & 3,65 & 4,48 \\
\hline ex paragi & 60 & 53 & 24,92 & 4,66 & 08 & 30 & 3,41 & 3,83 \\
\hline $\begin{array}{l}\text { rypt } \\
\text { sche }\end{array}$ & 94 & & & 08 & 23 &, 77 & 4,09 & 3,76 \\
\hline $\begin{array}{l}\text { Sebas } \\
\text { comm }\end{array}$ &, 06 & 4,07 & 15,18 & 2,84 & 1,85 & 3,94 & 4,01 & 3,62 \\
\hline $\begin{array}{l}\text { Sebas } \\
\text { brasill }\end{array}$ &, 77 & 4,41 & 1,12 & 4,51 & 0,41 & 0,88 & 65 & 3,27 \\
\hline $\begin{array}{l}\text { Nectal } \\
\text { megar }\end{array}$ & 70 & 0 & 8 & 3,10 & 17 & 51 & 50 & 2,70 \\
\hline Ocote & 18,09 & 2,30 & 15,48 & 2,89 & 1,35 & 2,89 & 2,59 & 2,69 \\
\hline Sipho & 25,73 & 3,27 & 14,37 & 2,69 & 0,95 & 2,03 & 2,65 & 2,66 \\
\hline Euger & 52 & & 1568 & 293 & 0,47 & 0,99 & 2,05 & 2,35 \\
\hline $\begin{array}{l}\text { Eugenic } \\
\text { uruguas }\end{array}$ & & 9 & & 2,71 & 59 & 1,26 & 92 & 2,18 \\
\hline Lamal & 13,37 & 1,70 & 10,75 & 2,01 & 0,94 & 2,00 & 1,85 & 1,90 \\
\hline Dicks & 98 & 2,03 & 9,75 & 1,82 & 0,75 & 1,61 & 1,82 & 1,82 \\
\hline Podo & & & & & 38 & 1,88 & 78 & 1,75 \\
\hline $\begin{array}{l}\text { Matayk } \\
\text { elaeag }\end{array}$ & 08 & 1 & 15 & 1,90 & 50 & 1,08 & 1,50 & 1,63 \\
\hline $\begin{array}{l}\text { Myrc } \\
\text { cucul }\end{array}$ & 15,48 & 1,96 & 6 & 2,18 & 23 & 0,50 & ,23 & 1,55 \\
\hline Ocol & & & +4 & 1,39 & 95 & 2,02 & 1,63 & 1,55 \\
\hline $\begin{array}{l}\text { Cam, } \\
\text { rhom }\end{array}$ & 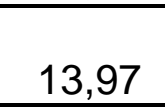 & - & rove & 5 & 36 & 0,77 & ,27 & 1,50 \\
\hline $\begin{array}{l}\text { Cinnal } \\
\text { glaziol }\end{array}$ & ,96 & 9 & 4 & 1,45 & 61 & 1,30 & 1,34 & 1,38 \\
\hline $\begin{array}{l}\text { Camp } \\
\text { xanth }\end{array}$ & 12,16 & 1,54 & ,44 & 1,58 & 0,37 & 0,79 & ,17 & 1,31 \\
\hline Luehea divaricat & 11,96 & 1,52 & 6,13 & 1,15 & 0,47 & 1,00 & 1,26 & 1,22 \\
\hline Sapiu & 9,85 & 1,25 & 7,64 & 1,43 & 0,44 & 0,94 & 1,10 & 1,21 \\
\hline Roup & 9,75 & 1,24 & 7,54 & 1,41 & 0,32 & 0,67 & 0,96 & 1,11 \\
\hline Prunus myr & 8,24 & 1,05 & 7,44 & 1,39 & 0,29 & 0,62 & 0,84 & 1,02 \\
\hline ubtotal 1 & 26,53 & 79,53 & 404,62 & 75,67 & 41,74 & 89,25 & 84,40 & 81,50 \\
\hline ubto & 161,43 & 20,46 & 129,98 & 24,37 & 5,02 & 10,78 & 15,68 & 18,50 \\
\hline otal & ,94 & 100 & 534,67 & 100 & 46,76 & 100 & 100 & 100 \\
\hline
\end{tabular}

Onde: DA- Densidade Absoluta (ind/ha); DR- Densidade Relativa (\%); FA- Frequência Absoluta; FR-

Frequência Relativa(\%); DoA-Dominância Absoluta ( $\left.\mathrm{m}^{2} / \mathrm{ha}\right)$; DoR- Dominância Relativa (\%); VC- Valor de cobertura (0-100\%); VI- Valor de Importância (0-100\%). 
A floresta de São Francisco de Paula apresentou densidade intermediária (818,81 ind/ha no ano de 2000 e 787,94 ind/ha em 2009), quando comparada ao estudo de SANQUETTA et al., (2003), que avaliando o estrato arbóreo (DAP $\geq 10 \mathrm{~cm}$ ) em dois remanescentes de Floresta com Araucária no estado do Paraná, observaram 517,5 ind/ha no primeiro remanescente e 925 ind/ha no segundo.

Corroborando com SAWCZUK (2009) que identificou redução relativa na densidade da floresta em 2,4\% no período de seis anos, na Flona de São Francisco de Paula, observou-se uma redução do número de indivíduos igual a $3,8 \%$, interpretada também como uma redução de 30,9 ind/ha entre os anos de 2000 a 2009. SANQUETTA et al., (2003) observaram comportamento contrário, com aumento de densidade de 388,25 ind/ha em 1998 para 517,5 ind/ha em 2007 em remanescentes das cidades paranaenses de General Carneiro e Coronel Domingos Soares, sendo o mesmo observado para o remanescente de São João do Triunfo, com aumento de densidade de 693,71 ind/ha em 1998, para 925 ind/ha em 2007, configurando conforme explicado pelos autores, um amplo processo de regeneração natural após um histórico de exploração seletiva.

A vegetação da Flona de São Francisco de Paula indicou um aumento de 9,6\% na dominância absoluta. SCHAAF et al., (2006) e SAWCZUK (2009) encontraram um aumento desse mesmo parâmetro igual a 21,3\% em 21 anos e $5,1 \%$ em seis anos, respectivamente. Uma analogia sumária permite inferir um crescimento em área basal na ordem de aproximadamente um ponto percentual ao ano nesses três estudos.

A. angustifolia manteve o maior $\mathrm{VI}$ em todos os anos amostrados (média de $19,75 \%$, com pequeno desvio padrão de $0,27 \%$ ), sendo que o valor deste índice sempre se manteve superior a três vezes ao segundo maior $\mathrm{VI}$, representado por $B$. salicifolius, alternando com $I$. brevicuspis. A. angustifolia também manteve a dominância absoluta superior de $30 \%$ em todos os anos amostrados. Apesar da redução de 6,5\% do número de indivíduos (103,4 ind/ha em 2000, para 96,7 ind/ha em 2009), a dominância absoluta da espécie apresentou aumento de $15 \%$ no mesmo período $\left(14,12 \mathrm{~m}^{2} / \mathrm{ha}\right.$, para $\left.16,81 \mathrm{~m}^{2} / \mathrm{ha}\right)$, demonstrando que o seu incremento em diâmetro na área não se deve ao recrutamento de novos indivíduos da espécie e, sim, ao crescimento daqueles já estabelecidos no local. No entanto, para a espécie $C$. decandra, o aumento de sua dominância e VI ocorreu devido ao grande número de recrutamentos.

Logo, as características observadas para $A$. angustifolia corroboram com 0 estudo de SOARES (1979), no qual o autor afirma que a espécie vem sendo naturalmente substituída pelo avanço das espécies latifoliadas. O mesmo autor salienta que em todo continente americano na associação entre coníferas e folhosas, as folhosas representam as espécies clímax.

De modo geral, as espécies sofreram poucas alterações em seus VI nos dez anos estudados, sendo que a $A$. angustifolia, B. salicifolius, C. decandra, C. aschersoniana, I. brevicuspis, I. paraguariensis, O. pulchella, S. brasiliensis, S. commersoniana e $S$. reitzii, mantiveram a soma de seus respectivos $\mathrm{VI}$, correspondentes a no mínimo $50 \%$ do valor encontrado para toda a floresta, consideradas por esse motivo, como as mais importantes da área. Além dessas, destacam-se: N. megapotamica, E. psidiiflora, E. uruguayensis, L. ternata, $D$. sellowiana, P. lambertii, M. elaeagnoides, M. cucullata, O. puberula, C. rhombea, C. glaziovii, C. xanthocarpa, L. divaricata, S. glandulosum, R. montana, P. myrtifolia e V. discolor.

Embora a migração entre classes de VI aparentemente possa parecer pouco 
significante para as espécies mais representativas, estas migrações são fundamentais, pois indicam modificações profundas na estrutura e composição. Como exemplo, tem-se $C$. decandra, que apresentou maior plasticidade na estrutura horizontal da floresta, pois no ano de 2000 , apresentava o sexto maior VI (3,54\%), já para o ano de 2007, apresentava o quarto maior VI, mantendo essa posição até o ano de 2009 (4,48\%). Dessa forma, atribui-se a esse comportamento devido seu incremento em área basal de $0,49 \mathrm{~m}^{2} / \mathrm{ha}$ (ano de 2000) para 0,65 $\mathrm{m}^{2} / \mathrm{ha}(2009) \mathrm{e}$, essencialmente a sua densidade absoluta, que passou de 35,21 ind/ha (2000) para 46,63 ind/ha (2009).

A I. paraguariensis também apresentou elevada plasticidade na floresta, passando de oitavo maior VI em 2000 (3,44\%), para quinto VI em 2009 (3,83\%), valoração que pode ser atribuída ao incremento em área basal, que passou de 0,87 $\mathrm{m}^{2} /$ ha (ano de 2000) para 1,08 $\mathrm{m}^{2} / \mathrm{ha}$ em 2009, somado a este, o acréscimo de densidade, que aumentou de 31,99 ind/ha (ano de 2000) para 35,68 ind/ha em 2009. Outra espécie que seguiu a mesma tendência foi a $N$. megapotamica, que passou do $12^{\circ}$ maior VI (2,39\% em 2000), para o nono maior VI, em 2009 (2,7\%).

Por outro lado, espécies como $S$. brasiliensis e $S$. commersoniana apresentaram desvaloração de sua importância no período estudado, cedendo sua "representatividade" na floresta para espécies emergentes. Embora tenha apresentado estabilidade em seus VI, entre 2000 e 2004, a partir de 2005 ocorreu gradativa perda de densidade, dominância e frequência para as duas espécies, em que $S$. brasiliensis passou do sétimo maior VI em 2000, para o oitavo em 2009. A espécie $S$. commersoniana, por sua vez, no ano de 2000 apresentava o quinto maior VI, em 2009 decresceu duas posições, com redução de $12,5 \%$ em sua densidade absoluta.

Analisando graficamente a relação entre dominância absoluta e densidade absoluta (Figura 3), verificou-se uma relação inversamente proporcional até o ano de 2005, ponto que atinge o menor número de indivíduos na floresta, e que o crescimento em área transversal manteve-se praticamente estagnado. No ano seguinte (2006), observou-se um comportamento diretamente proporcional, ou seja, houve um aumento na densidade de indivíduos e também em dominância. No ano de 2007, ocorreu um considerável aumento na densidade, porém os valores relativos à dominância permanecem praticamente inalterados. No ano de 2008, observou-se novamente a relação de proporcionalidade inversa entre os parâmetros, com redução da densidade e aumento da dominância, mantendo estável a densidade e indicando aumento na dominância para o ano de 2009.

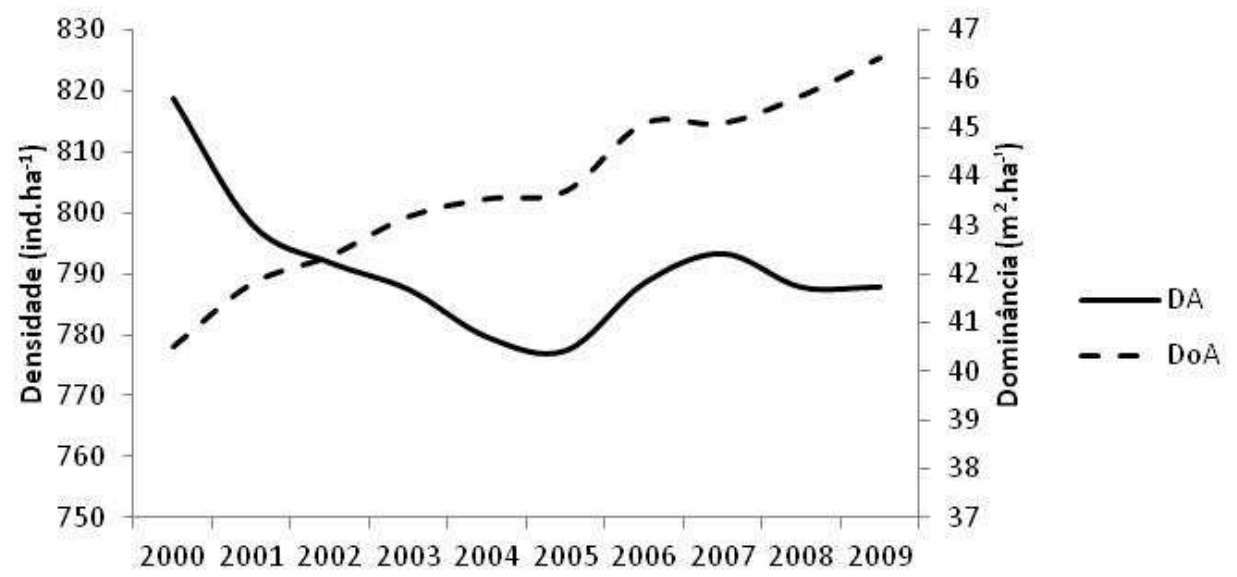

FIGURA 3 - Relação entre Dominância Absoluta e Densidade Absoluta entre os anos de 2000 a 2009. 
Por meio da análise gráfica, identifica-se a redução de densidade mais intensamente entre os anos de 2000 a 2005, posteriormente acompanhado de um aumento, atribuído essencialmente ao recrutamento de indivíduos da espécie $C$. decandra, justificando com isso o aumento do Valor de Importância desta espécie. Observa-se o avanço sucessional da floresta, em que a gradual redução de densidade é acompanhada do aumento de área basal. Nesse sentido GENTRY \& TERBORGH (1990) citam que o crescimento diamétrico em florestas, associado com redução quanto ao número de indivíduos, caracteriza o avanço sucessional do ciclo silvigenético.

De forma a complementar a análise, a avaliação da dinâmica da mortalidade e do recrutamento é essencial, por considerar a capacidade regenerativa da floresta, além de propiciar uma melhor compreensão dos processos naturais. Os valores referentes à mortalidade e recrutamento em cada ano inventariado estão descritos na Tabela 4. Também são avaliadas as taxas referentes à mortalidade e recrutamento.

TABELA 4 - Valores referentes a mortalidade e recrutamento anuais (ha), entre os anos de 2001 e 2009

\begin{tabular}{lrrrrrrrrrr}
\hline \multicolumn{1}{c}{ Ano } & $\mathbf{2 0 0 1}$ & $\mathbf{2 0 0 2}$ & $\mathbf{2 0 0 3}$ & $\mathbf{2 0 0 4}$ & $\mathbf{2 0 0 5}$ & $\mathbf{2 0 0 6}$ & $\mathbf{2 0 0 7}$ & $\mathbf{2 0 0 8}$ & $\mathbf{2 0 0 9}$ & Total \\
\hline Indivíduos Mortos & 17,1 & 14 & 10,7 & 12 & 7,8 & 19,4 & 7,2 & 12,1 & 9,2 & 109,5 \\
\hline Taxa de mortalidade (\%) & 2,4 & 1,9 & 1,5 & 1,7 & 1,1 & 2,6 & 1,0 & 1,7 & 1,2 & \\
\hline Indivíduos Recrutados & 2,4 & 10,6 & 6,7 & 4,9 & 6,3 & 32,3 & 12,1 & 7,8 & 5,8 & 88,9 \\
\hline $\begin{array}{l}\text { Taxa de recrutamento } \\
\text { (\%) }\end{array}$ & 0,3 & 1,5 & 0,9 & 0,7 & 0,9 & 4,3 & 1,7 & 1,1 & 0,8 & \\
\hline
\end{tabular}

A análise da mortalidade indicou um valor total de 109,5 ind/ha entre os anos de 2001 a 2009, indicando uma média anual de 12,2 ind/ha. Já os recrutamentos, indicaram um valor inferior, total de 88,9 ind/ha no mesmo período, e uma média anual de 9,9 ind/ha. O maior número de mortalidade sobre o recrutamento corresponde a uma redução de 20,6 ind/ha durante o período avaliado.

Observando o balanço referente ao número de recrutamentos menos o número de mortalidades (Figura 4), observa-se que durante a maior parte do período a mortalidade manteve número superior ao recrutamento (período de 2001 a 2005, e, 2008 a 2009), propiciando a redução de densidade. A entrada de novos indivíduos na floresta, por meio de recrutamento, foi observada entre os anos de 2005 a 2007, sendo que em 2006, além de ter ocorrido o maior valor de mortalidade, ocorreu também maior valor de recrutamento, superando em grande número a mortalidade. 


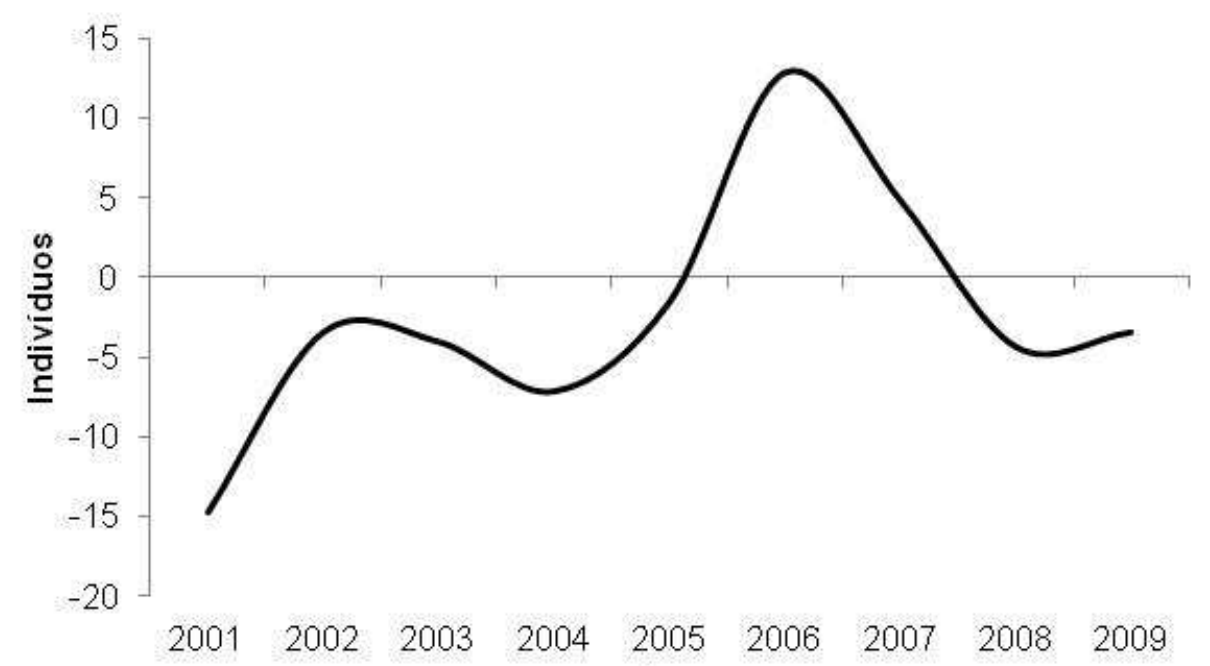

FIGURA 4 - Balanço entre recrutamento e mortalidade, entre os anos de 2001 a 2009

Embora no período analisado não possa ser definida uma tendência quanto ao balanço da floresta, atribuída ao variável número de recrutamentos e mortalidade, estudos demonstram que a estrutura da floresta madura segue um padrão, mantendo sua densidade, área basal e número de espécies flutuando em torno de um número médio, ao longo do tempo (ROLIM et al., 1999). Os mesmos autores, afirmam que distúrbios devido a prolongados períodos de seca estão amplamente distribuídos na região tropical, interferindo no padrão estrutural de florestas. Nesse sentido, a compreensão das respostas da floresta frente às variáveis meteorológicas é essência para análise nas decisões relacionadas à silvicultura e avaliações de possíveis efeitos nas mudanças ambientais e crescimento das populações (CUSATIS et al., 2013).

Considerando os valores de recrutamentos e mortalidade, com os relacionados a precipitação para o mesmo período (Figura 5), estabelece-se uma assimetria, em que os períodos de menor precipitação são acompanhados por maior mortalidade (ano de 2006 e 2008). A mesma proporcionalidade não foi observada para os recrutamentos, embora estes apresentem simetria entre os anos de 2001 a 2005, o ano subsequente que apresenta menor precipitação (ano de 2006), foi observado o maior recrutamento do período. A possível explicação para a assimetria do recrutamento e precipitação pode ser atribuída a dois aspectos: a desuniformidade temporal das chuvas, e, ao crescimento das árvores. 


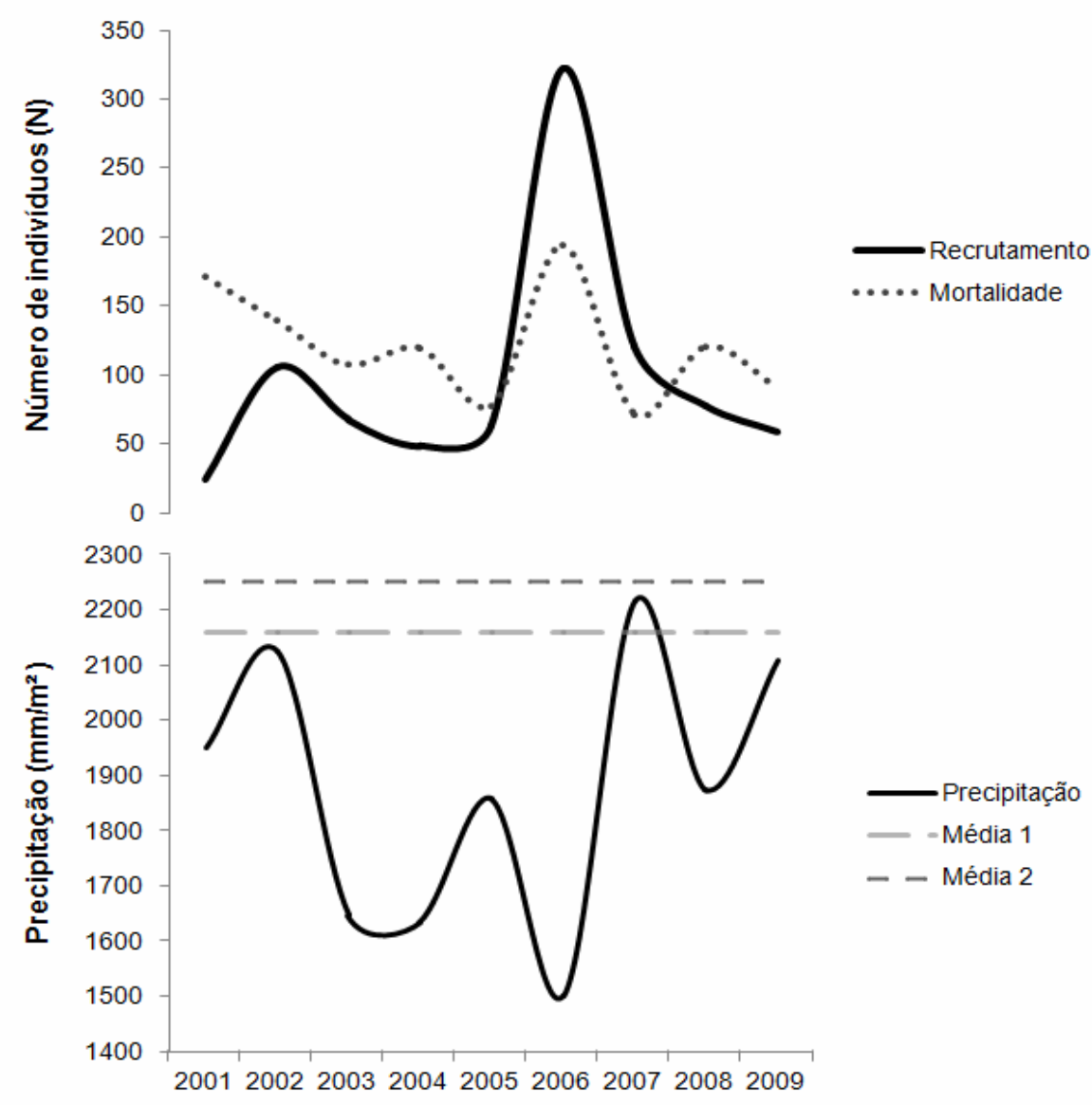

FIGURA 5 - Relação entre recrutamento, mortalidade e precipitação, entre os anos de 2001 a 2009

Onde: Precipitação - precipitação pluvial anual observada $\left(\mathrm{mm} / \mathrm{m}^{2}\right)$; Média 1- Precipitação pluvial anual observada por MALUF (1999); Média 2 - Precipitação pluvial anual observada por NIMER (1990).

A precipitação anual no período indicou valores abaixo dos considerados normais por MALUF (1999) e NIMER (1990), a exceção de 2007, onde a precipitação total anual apresentou-se acima da média descrita apenas por MALUF (1999). Os menores valores de precipitação podem ser observados no ano de 2006 $\left(1.504 \mathrm{~mm} / \mathrm{m}^{2}\right)$, e entre os anos de $2003\left(1.649 \mathrm{~mm} / \mathrm{m}^{2}\right)$ e $2004\left(1.637 \mathrm{~mm} / \mathrm{m}^{2}\right)$. Considerando ainda as precipitações anuais, o regime de chuvas não ocorreu de maneira uniforme entre os meses de cada ano. O período referente ao final do segundo semestre de 2005, no qual houve a retomada do período chuvoso, ocorreram valores pluviométricos próximos aos normais, o que pode ter favorecido a retomada do crescimento diamétrico da floresta após o período de seca, anteriormente constatado, favorecendo o recrutamento dos indivíduos observados no ano de 2006.

O segundo aspecto consiste na baixa precipitação acumulada entre os anos de 2003 e 2004, reduzindo as atividades fisiológicas, gerando um estado de estagnação do crescimento florestal. Logo, o período desfavorável para o crescimento foi ligeiramente interrompido pelo aumento da precipitação em 2005, fazendo com que ocorresse um rápido crescimento pela liberação fitohormonal, ocasionando um grande recrutamento entre 2005 e 2006. 
O Coeficiente de Correlação de Pearson indicou alto valor entre mortalidade e recrutamento $(0,77$, para $\mathrm{P}<0,05)$, corroborando com o observado por ROLIM et al., (1999). No entanto não foram estabelecidas correlações entre a dinâmica de recrutamento e mortalidade com as variáveis climáticas. Isto pode ser atribuído à pequena quantidade de variáveis constituintes da matriz de dados referentes aos recrutamentos e mortalidade, não sendo capaz de absorver as interações entre as variáveis. Esta análise evidencia a importância do levantamento contínuo de informações a respeito dos processos dinâmicos da floresta, que possibilitem uma análise mais ampla no sentido temporal, permitindo aplicar modelos matemáticos capazes de contemplar as interações da floresta e o ambiente.

Em relação à composição florística, a mortalidade foi representada por 95 espécies, sendo as espécies mais representativas com relação ao número total de indivíduos mortos: S. brasiliensis responsável por $12,5 \%, A$. angustifolia $(6,9 \%), M$. cucullata $(4,8 \%)$, C. decandra $(4,2 \%), C$. aschersoniana (2,9\%), S. commersoniana $(2,9 \%)$, B. salicifolius (2,8\%) e demais espécies representando 62,9\% (Figura 6).

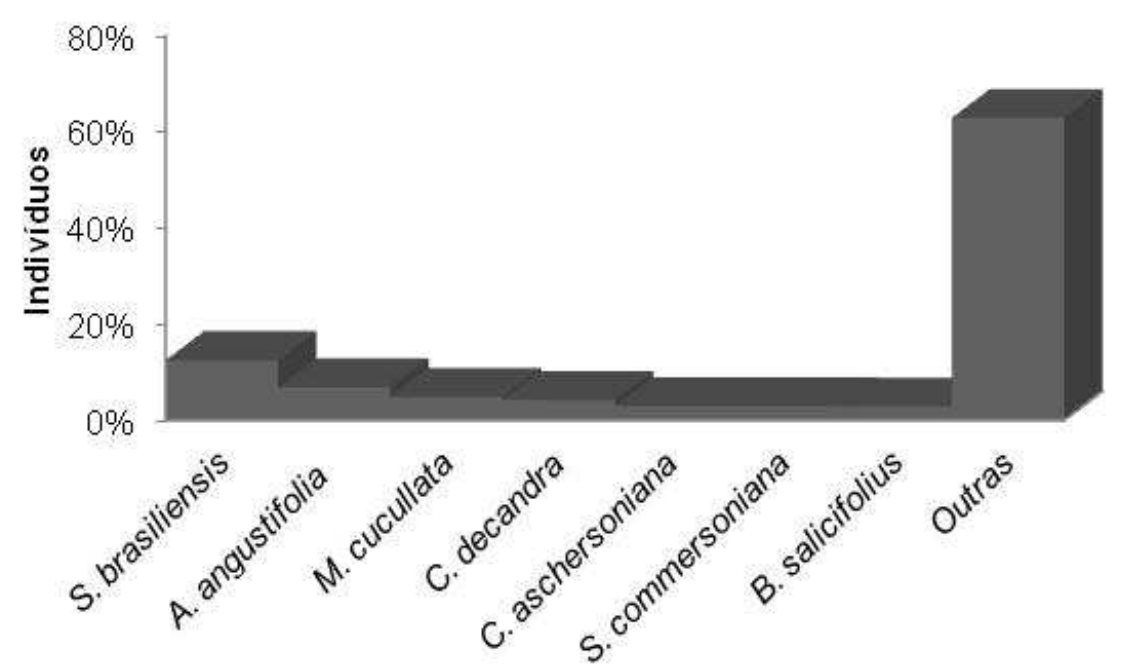

FIGURA 6 - Porcentagem do número de indivíduos mortos por espécie entre os anos de 2001 a 2009

Por meio da análise das espécies que representam maior mortalidade, observa-se uma estreita relação entre aspectos ecológicos, em que o gênero Sebastiania, responsável por $15,4 \%$ de toda mortalidade sofreu forte influência devido a baixa precipitação. Corroborando com o observado, CARVALHO (2003) cita que o gênero Sebastiania é muito comum em orlas dos sub-bosques, em solos úmidos e nas matas baixas de beira de rio e riachos, onde o solo se encontra temporariamente alagado e com lençol freático superficial.

A. angustifolia por sua vez, apresenta o segundo maior valor relativo à mortalidade $(6,9 \%)$, o que pode ser atribuído a sua elevada densidade, acentuada a sua condição de "vanguarda" no estabelecimento da floresta, onde gradualmente cede seu espaço para espécies latifoliadas. Esta observação pode ser evidenciada quando considerado que a mortalidade desta espécie ocorreu quase que na totalidade, nos indivíduos com menores diâmetros e que o recrutamento dessa espécie foi responsável por apenas $1 \%$ do total.

Considerando a mortalidade entre as famílias botânicas, observa-se que 
Myrtaceae foi a que apresentou maior porcentagem com $26,2 \%$ do total, o que pode ser justificado devido à grande abundância de indivíduos dessa família, e também por apresentar grande número de indivíduos em classes diamétricas inferiores. Euphorbiaceae apresentou $17,4 \%$ da mortalidade, devido à forte representatividade do gênero Sebastiania. A família Lauraceae apresentou a terceira maior mortalidade, com $7,67 \%$, devido essencialmente à mortalidade da espécie $C$. aschersoniana. Araucariaceae, por sua vez, com apenas uma espécie representou $6,8 \%$ da mortalidade. As demais famílias representaram juntas $41,9 \%$ do total.

Com relação aos grupos ecológicos, a mortalidade foi superior para o grupo secundário tardio (41\%), seguido pelo grupo secundário inicial (24\%), climáxico $(23 \%)$ e pioneiro (11\%) (Figura 7 ).

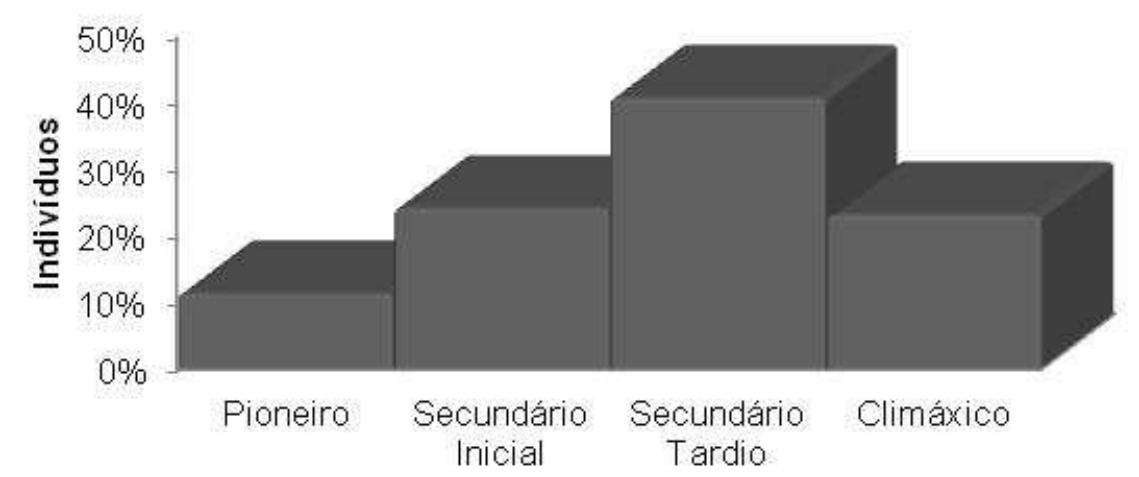

FIGURA 7 - Frequência da mortalidade por grupos ecológicos entre os anos de 2001 a 2009

O grupo das secundárias tardias foi representado principalmente pela espécie S. brasiliensis, responsável por $33 \%$ dos indivíduos do grupo. A espécie com maior representatividade no grupo das secundárias iniciais foi a C. Decandra, representando $19 \%$ do total de indivíduos. A mortalidade no grupo das climáxicas foi representada em sua maior parte pela espécie C. aschersoniana (14\% do total). As pioneiras, por sua vez, foram representadas essencialmente pela espécie $D$. spinescens $(27 \%$ do total), sendo este grupo caracterizado por um rápido ciclo de vida, condicionando sua presença na floresta no advento da abertura de clareiras.

Considerando os recrutamentos, a composição florística foi representada por 77 diferentes espécies, pertencentes a 33 famílias botânicas. A espécie com maior número de recrutamentos foi $C$. decandra perfazendo $21,7 \%$ do total, $S$. brasiliensis $(12,5 \%)$, I. paraguariensis $(7 \%), M$. elaeagnoides $(4,8 \%), C$. glaziovi $(3,8 \%), N$. megapotamica (3,3\%), M. cucullata (2,9\%), as demais espécies somaram juntas 44 $\%$. (Figura 8). Algumas das espécies com elevado número de recrutamentos, também se caracterizam por elevada mortalidade, como por exemplo, C. decandra, $S$. brasiliensis, $M$. cucullata, o que indica um equilíbrio de suas densidades. 


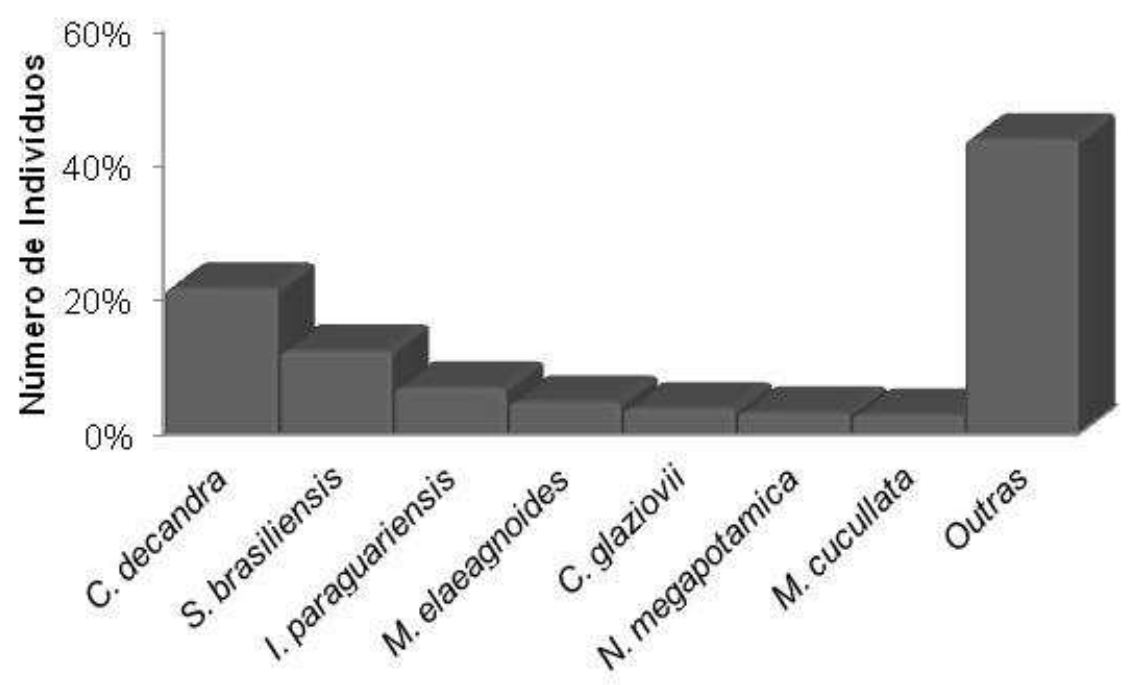

FIGURA 8 - Porcentagem dos indivíduos recrutados por espécie, entre os anos de 2001 a 2009

A distribuição dos recrutamentos entre as famílias indica maior representatividade da família Salicaceae $(23,2 \%)$ devido essencialmente ao número de recrutamentos da espécie $C$. decandra. $O$ mesmo pode ser atribuído à família Euphorbiaceae $(13,7 \%)$ com relação à espécie $S$. brasiliensis. Embora a família Myrtaceae só tenha uma espécie com elevado número de recrutamentos $(M$. cucullata), o grande número de outras espécies que constituem essa família conferiu a ela o segundo maior recrutamento, com $17,2 \%$ do total, corroborando em parte com o observado na análise florística. Cabe destaque as demais famílias como: Luraceae que representou 10,4\%, Aquifoliaceae (8,9\%), Sapindaceae $(6,7 \%)$, Primulaceae $(3 \%)$, Annonaceae $(1,6 \%)$, Cunoniaceae $(1,6 \%)$, Rosaceae $(1,6 \%)$, Rutaceae $(1,4 \%)$, Fabaceae $(1,2 \%)$ e Solanaceae $(1 \%)$. As demais famílias somaram juntas $8,5 \%$.

Da mesma forma como observado na composição dos grupos ecológicos para toda floresta e mortalidade, os recrutamentos mantiveram o grupo secundário tardio como o de maior representatividade (42\%) (Figura 9). Os demais grupos foram: secundárias iniciais (35\%), climáxicas (18\%) e pioneiras (4\%).

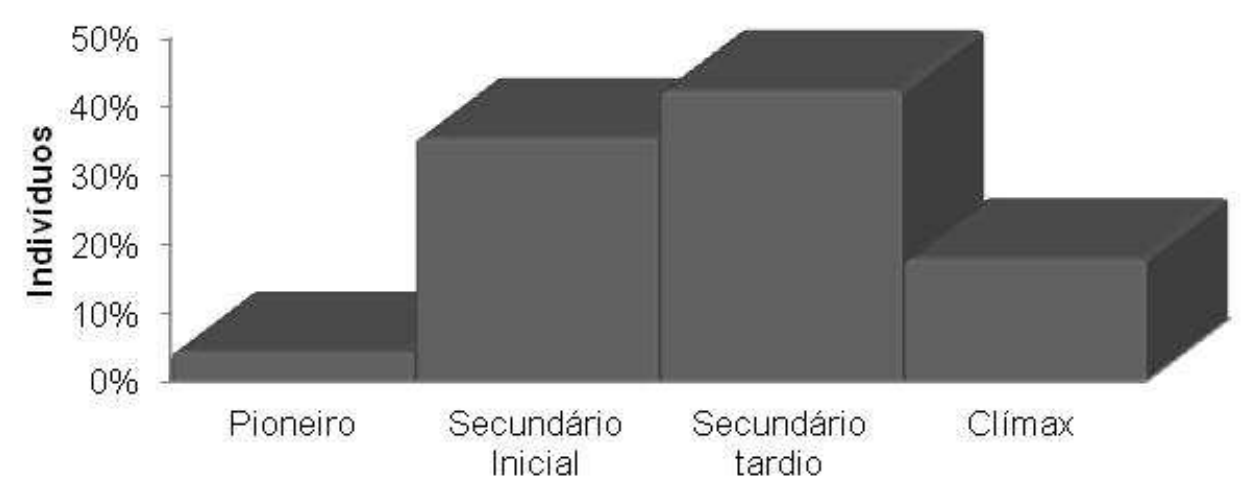

FIGURA 9 - Frequência do recrutamento por grupos ecológicos entre os anos de 2001 a 2009 
As espécies recrutadas mais representativas de cada grupo foram $S$. brasiliensis (30\% do total de indivíduos secundários tardios), C. decandra (62\% do total de indivíduos secundários tardios), M. cucullata (17\% do total entre o grupo climáxico) e S. sanctae-catharinae, representando $16 \%$ dos indivíduos pioneiros.

Ainda que a análise do total de indivíduos recrutados e mortos indique um avanço sucessional, o número de indivíduos recrutados por grupos ecológicos contraria, em parte, essa lógica, visto que era esperado um maior número de recrutamentos de indivíduos clímax. No entanto, as condições ambientais referentes ao período inventariado favoreceram o maior recrutamento de espécies arbóreas secundárias, salientando a resiliência da floresta, cuja resposta dinâmica é feita de acordo com a disponibilidade ou não dos recursos ambientais (EBLING et al., 2013). Considerando ainda que as avaliações foram constituídas a partir de um diâmetro mínimo de $9,5 \mathrm{~cm}$, o banco de plântulas da floresta, que futuramente irá compor os estratos superiores, pode apresentar uma constituição florística diferenciada da atual. Logo, o inventário das alterações florísticas e estruturais deve ser feito de maneira continuada, propiciando um melhor entendimento do avanço sucessional.

\section{CONCLUSÕES}

A floresta apresentou pequenas alterações acerca de sua composição florística e estrutura horizontal nos 10 anos avaliados. Entre as espécies que compõe o estrato arbóreo, $C$. decandra apresentou mobilidade em seu valor de importância na floresta, indicando adaptação às condições ambientais. Embora $A$. angustifolia seja a espécie mais importante da floresta, observou-se redução de sua densidade, indicando sua gradual substituição por espécies latifoliadas. O grande número de indivíduos da família Myrtaceae conferiu a esta a maior importância dentre as famílias.

A floresta mostra predomínio de espécies secundárias tardias, com tendência do grupo se manter em maior número nos próximos anos, devido ao superior número de recrutamentos deste grupo.

Embora os valores relacionados a recrutamento e mortalidade apresentem flutuações ao longo do período analisado, verifica-se maior mortalidade, corroborando com a redução de densidade. Os valores relacionados à mortalidade $\mathrm{e}$ recrutamento também mostraram grande simetria de sua flutuação de acordo com os valores de precipitação pluviométrica. Diferentemente do observado para a densidade, ocorreu 0 aumento de área transversal, caracterizando o avanço sucessional da floresta, que no decorrer do tempo assume cada vez mais as características de sua configuração primária.

Neste sentido, o monitoramento contínuo da floresta, com maior amplitude temporal se faz necessário para consolidar essas observações, possibilitando um melhor entendimento da dinâmica florestal e suas interações com o meio.

\section{REFERÊNCIAS}

APG III. Angiosperm Phylogeny Group. An update of the angiosperm phylogeny group classification for the orders and families of flowering plants: APG III. Botanical Journal of the Linnean Society, v.161, p.105-121, 2009. 
BUDOWSKI, G.N. Distribution of tropical American rain forest species in the light of sucesión processes. Turrialba, v.15, n.2, p.40-52, 1965.

CARVALHO, P.E.R. Espécies florestais brasileiras: recomendações silviculturais, potencialidades e uso da madeira. Colombo: EMBRAPA-CNPF, 1994.

CARVALHO, P.E.R. Espécies arbóreas brasileiras. v.1. Brasília: Embrapa Informações Tecnológicas, 2003.1039p.

CARVALHO, P.E.R. Espécies arbóreas brasileiras. v.2. Brasília: Embrapa Floresta, 2006. 627p.

CARVALHO, P.E.R. Espécies arbóreas brasileiras. v.3. Brasília: Embrapa Informações Tecnológicas, 2008. 593p.

CHAMI, L.B.; ARAÚJO, M.M.; LONGHI, J.J.; KIELSE, P.; LÚCIO, A.D. Mecanismos de regeneração natural em diferentes ambientes de remanescente de Floresta Ombrófila Mista, São Francisco de Paula, RS. Ciência Rural, v.41, n.2, p.251-259, 2011.

CUSATIS, A.C.; TRAZZI, P.A.; DOBNER JR., M; HIGA, A.R. Dendroecologia de Cedrela fissilis na Floresta Ombrófila Mista. Pesquisa Florestal Brasileira, v.33, n.75, p.287-297, 2013.

DURIGAN, M.E. Florística, dinâmica e análise protéica de uma Floresta Ombrófila Mista em São João do Triunfo - PR. 1999. 125 f. Dissertação (Mestrado em Ciências Florestais) - Universidade Federal do Paraná, Curitiba, PR.

EBLING, Â.A.; WATZLAWICK, L.F.; RODRIGUES, A.L.; LONGHI, S.J.; LONGHI, R.V.; ABRÃO, S.F. Acuracidade da distribuição diamétrica entre métodos de projeção em Floresta Ombrófila Mista. Ciência Rural, v.42, n.6, p.1020-1026, 2012.

EBLING, Â.A; PÉLLICO NETTO, S.; WATZLAWICK, L.F.; MIRANDA, R.O.V.; ABRÃO, S.F. Ecologia e projeção diamétrica de três grupos arbóreos em remanescente de floresta Ombrófila Mista em São Francisco de Paula, RS. Floresta, v. 43, n. 2 , p. $261-270,2013$.

GALVÃO, F.; AUGUSTIN, C. A gênese dos campos sulinos. Floresta, v.41, n.1, p.191-200, 2011.

GENTRY, A. H.; TERBORGH, J. Composition and dynamics of the Cosha Cashu mature. In: Four Neotropical rainforests. New Haven: Yale University Press. 1990. p. 542-564.

HART SHORN, G. S. Tree falls and tropical forest dynamics. In: Tropical trees as living systems. New York: Cambridge University Press. 1978. p. 617-638.

HERRERA, H.; ROSOT, N.C.; ROSOT, M.A.D.; OLIVEIRA, M.Y.Y. Análise florística e fitossociológica do componente arbóreo da Floresta Ombrófila Mista presente na 
reserva florestal EMBRAPA/EPAGRI, Caçador, SC - Brasil. Revista Floresta, v.39, n.3, p.485-500, 2009.

KANIESKI M.R.; ARAÚJO, A.C.B.; LONGHI, S.J. Quantificação da diversidade em Floresta Ombrófila Mista por meio de diferentes Índices Alfa. Scientia Forestalis, v.38, n.88, p.567-577, 2010.

KLEIN, R.M. O aspecto dinâmico do pinheiro brasileiro. Sellowia, v.12, n.12, p. 1748, 1960.

LIMA, T.E. de O.; HOSAKAWA, R.T.; MACHADO, S. do A.; KLOCK, U. Caracterização fitossociológica da vegetação no entorno de nascentes de um fragmento de Floresta Ombrofila Mista Montana na bacia do rio das Pedras, Guarapuava (PR). Ambiência, v.8, n.2, p.229-244, 2012.

LONGHI, S.J.; ARAUJO, M.M.; BRENA, D.A. Estudo de Dinâmica de Floresta Ombrófila Mista realizados em parcelas permanentes pela UFSM. In: Experiências de Monitoramento do Bioma Mata Atlântica com 0 uso de parcelas permanentes. Curitiba: Funpar, 2008. p.281-319.

LORENZI, H. Árvores brasileiras: manual de identificação e cultivo de plantas arbóreas do Brasil. v.1. 5ed. Nova Odessa: Instituto Plantarum, 2008. 384p.

MALUF, J.R.T. Nova classificação climática do Rio Grande do Sul. Passo Fundo: EMBRAPA. Disponível em: http://www.cnpt.embrapa.br/biblio/p_pa08.htm. 1999. Acesso em: 2 de fevereiro de 2014.

MOSCOVICH, F.A. Dinâmica de crescimento de uma Floresta Ombrófila Mista em Nova Prata, RS. 2006. 135 f. Tese (Doutorado em Engenharia Florestal) Universidade Federal de Santa Maria, Santa Maria, RS.

NIMER, E. Clima. In: IBGE. Instituto Brasileiro de Geografia e Estatística. Geografia do Brasil: Região Sul. Rio de Janeiro: IBGE, 1990. p.151-187.

PIRES, P. T. de L.; ZENI JR., D.M.;GAULKE, D. As unidades de conservação e a Floresta Ombrófila Mista no estado do Paraná. Ciência Florestal, v.22, n.3, p.589603, 2012.

RIO GRANDE DO SUL. Relatório Final do Inventário Florestal Contínuo do Rio Grande do Sul. Porto Alegre, Santa Maria: SEMA, 2002. 706p.

RIO GRANDE DO SUL. Diretrizes ambientais para restauração de matas ciliares. Porto Alegre: SEMA, 2007. 33p.

ROLIM, S.G.; COUTO, H.T.Z.; JESUS, R.M. Mortalidade e recrutamento de árvores na Floresta Atlântica em Linhares (ES). Scientia Forestalis, v.55, p.49-69, 1999.

SANQUETTA, C. R.; DALLA CÔRTE, A.P.; EISFELD, R.L. Crescimento, mortalidade e recrutamento em duas florestas de Araucária (Araucaria angustifolia (Bert.) $\mathrm{O}$. Ktze.) no Estado do Paraná, Brasil. Revista Ciências Exatas e Naturais, v.5, n.1, 
2003.

SAWCZUK, A.L. Alteração na florística e estrutura horizontal de um fragmento de Floresta Ombrófila Mista na Floresta Nacional de Irati, Estado do Paraná. 2009. 164 f. Dissertação (Mestrado em Ciências Florestais) - Universidade Estadual do Centro Oeste do Paraná, Irati- PR.

SCHAAF, L.B.; FIGUEIREDO FILHO, A.; GALVÃO, F.; SANQUETTA, R.C. Alteração na estrutura diamétrica de uma floresta Ombrófila Mista no período entre 1979 e 2000. Revista árvore, v.30, n.2, p.283-295, 2006.

SCHNEIDER, P.R.; FINGER, C.A.G. Manejo sustentado de florestas inequiâneas heterogêneas. Santa Maria: UFSM, 2000.195p.

SFB - Serviço Florestal Brasileiro. Florestas do Brasil em resumo - 2010: dados de 2005-2010. Brasília: Serviço Florestal Brasileiro, 2010. 156p.

SOARES, R.V. Considerações sobre a regeneração natural da Araucaria angustifolia. Revista floresta, v.10, n.2, p.11-18, 1979.

SOBRAL, M.; JARENKOW, J.A.; BRACK, P.; IRGANG, B.E., LAROCCA, J.; RODRIGUES, R.S. FLORA arbórea e arborescente do Rio Grande do Sul, Brasil. São Carlos: RiMA, 2006. 350p.

STEPKA, T.F. Modelagem da dinâmica e prognose da estrutura diamétrica de uma Floresta Ombrófila Mista por meio de Matriz de Transição e Razão de Movimentação. 2008. 138 f. Dissertação (Mestrado em Ciências Florestais) Universidade Estadual do Centro Oeste do Paraná, Irati, PR.

VACCARO, S. Crescimento de uma floresta estacional decidual, em três estágios sucessionais, no município de Santa Tereza, RS, Brasil. 2002. 157 f. Tese (Doutorado em Engenharia Florestal) - Universidade Federal de Santa Maria, Santa Maria, RS.

WATZLAWICK, L.F. EBLING, Â.A.; RODRIGUES, A.L.; VERES, Q.J.I.V.; LIMA, A.M. Variação nos teores de carbono orgânico em espécies arbóreas da Floresta Ombrófila Mista. Floresta e Ambiente, v.18, n.3, p.248-258, 2011. 